Published in final edited form as:

Biochemistry. 2017 March 07; 56(9): 1248-1260. doi:10.1021/acs.biochem.6b00983.

\title{
X-ray Absorption Spectroscopy Reveals an Organometallic Ni-C Bond in the CO-Treated Form of Acetyl-CoA Synthase
}

\author{
Mehmet Can ${ }^{\dagger}$, Logan J. Giles ${ }^{\ddagger}$, , Stephen W. Ragsdale ${ }^{\star}, \dagger$, and Ritimukta Sarangi ${ }^{\star}, \ddagger$ \\ tDepartment of Biological Chemistry, University of Michigan, Ann Arbor, Michigan 48109-0606, \\ United States \\ FStanford Synchrotron Radiation Lightsource, SLAC National Accelerator Laboratory, Menlo Park, \\ California 94025, United States \\ $\S$ Department of Chemistry, Stanford University, Stanford, California 94306, United States
}

\begin{abstract}
Acetyl-CoA synthase (ACS) is a key enzyme in the Wood-Ljungdahl pathway of anaerobic $\mathrm{CO}_{2}$ fixation, which has long been proposed to operate by a novel mechanism involving a series of protein-bound organometallic ( $\mathrm{Ni}-\mathrm{CO}$, methyl-Ni, and acetyl-Ni) intermediates. Here we report the first direct structural evidence of the proposed metal-carbon bond. We describe the preparation of the highly active metal-replete enzyme and near-quantitative generation of the kinetically competent carbonylated intermediate. This advance has allowed a combination of $\mathrm{Ni}$ and $\mathrm{Fe} \mathrm{K}$ edge X-ray absorption spectroscopy and extended X-ray absorption fine structure experiments along with density functional theory calculations. The data reveal that $\mathrm{CO}$ binds to the proximal $\mathrm{Ni}$ of the six-metal metallocenter at the active site and undergoes dramatic structural and electronic perturbation in forming this organometallic $\mathrm{Ni}-\mathrm{CO}$ intermediate. This direct identification of a $\mathrm{Ni}-$ carbon bond in the catalytically competent CO-bound form of the A cluster of ACS provides definitive experimental structural evidence supporting the proposed organometallic mechanism of anaerobic acetyl-CoA synthesis.
\end{abstract}

\section{Graphical Abstract}

\footnotetext{
*Corresponding Authors: sragsdal@umich.edu. Phone: (734) 615-4621. Fax: (734) 763-4581., ritis@ slac.stanford.edu. Phone: (650) 926-4621.

ORCID

Stephen W. Ragsdale: 0000-0003-3938-8906

Author Contributions

M.C. and L.J.G. contributed equally to this work. R.S., S.W.R., L.G., and M.C. designed and performed the research. R.S., L.G., and M.C. analyzed the data.

Notes

The authors declare no competing financial interest.

Supporting Information

The Supporting Information is available free of charge on the ACS Publications website at DOI: 10.1021/acs.biochem.6b00983.

Figures S1-S4, Tables S1-S4, references, and a sample DFT input file (PDF)
} 


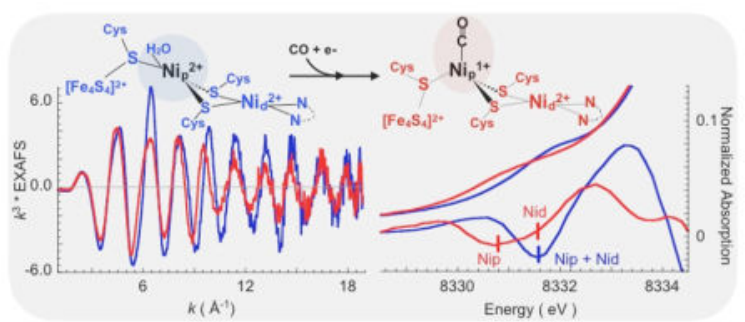

Thirty years ago, it was discovered that the nickel metalloenzyme $\mathrm{CO}$ dehydrogenase $(\mathrm{CODH})$, involved in the conversion of $\mathrm{CO}_{2}$ to $\mathrm{CO}$, also catalyzes an exchange reaction between $\mathrm{CO}$ and the carbonyl group of acetyl-CoA. ${ }^{1}$ The fact that $\mathrm{CODH}$ catalyzes this $\mathrm{CO}$ / acetyl-CoA exchange reaction demonstrated that this enzyme is solely responsible for binding the three components of acetyl-CoA (the carbonyl group, the methyl group, and $\mathrm{CoA}$ ) and catalyzing $\mathrm{C}-\mathrm{C}$ and $\mathrm{C}-\mathrm{S}$ bond formation. Thus, the protein was renamed acetylCoA synthase, and it was proposed that the ACS-catalyzed reaction occurs through a sequence of enzyme-bound organometallic reactions. ${ }^{1}$ Later, the ACS protein was demonstrated to exist within a tightly associated two-protein complex with separate CODH and ACS active sites, ${ }^{2,3}$ so it became known as CODH/ACS.

Structural and spectroscopic studies of the two components of the CODH/ACS complex have demonstrated that both proteins contain unique Ni-based active sites, working harmoniously to reduce $\mathrm{CO}_{2}$ to $\mathrm{CO}(\mathrm{CODH})$ and functionalize $\mathrm{CO}$ to acetyl-CoA (ACS). ${ }^{4}$ $\mathrm{X}$-ray crystallography revealed the active site of ACS, the so-called A cluster, to be a binuclear Ni center bridged through cysteine sulfur to a $4 \mathrm{Fe}-4 \mathrm{~S}$ subcluster [Figure 1, Protein Data Bank (PDB) entry 1OAO]. ${ }^{5-7}$ In this unusual metallocenter, the Ni distal to the FeS subcluster $\left(\mathrm{Ni}_{\mathrm{d}}\right)$ is coordinated to a tetradentate Cys-Gly-Cys sequence in a square-planar $\mathrm{N}_{2} \mathrm{~S}_{2}$ geometry, while the $\mathrm{Ni}$ proximal to the subcluster $\left(\mathrm{Ni}_{\mathrm{p}}\right)$, which is coordinated by three cysteine thiolates, can adopt a square-planar or tetrahedral geometry, a structural change that may be coupled to a significant conformational change in the ACS polypeptide. ${ }^{6,8}$

The proposed ACS reaction sequence (Figure 2, top panel), includes reductive activation of the active site $\mathrm{Ni}_{\mathrm{p}}(\mathrm{II})$ center (species $\mathbf{1}$ ) to transiently generate $\mathrm{Ni}_{\mathrm{p}}(\mathrm{I})$ (species 2 ), a reaction that is kinetically coupled to binding of $\mathrm{CO}$ to form the $\mathrm{Ni}_{\mathrm{p}}(\mathrm{I})-\mathrm{CO}$ intermediate (species 3 ), which is the intermediate characterized here. Then, addition of a methyl group generates methyl- $\mathrm{Ni}_{\mathrm{p}}-\mathrm{CO}$ species 4 that undergoes rapid reduction to form the more stable $\mathrm{Ni}_{\mathrm{p}}(\mathrm{II})$ species 5. C-C bond formation then ensues to generate acetyl-Ni (species 6 ) followed by CoA-dependent thiolysis to generate acetyl-CoA and regenerate active species 2 for the next round of catalysis. This is a simplified diagram because pulse-chase kinetic studies demonstrate that ACS follows a random sequential mechanism (Figure 2, bottom panel) in which both methylated and carbonylated forms of ACS can serve as the first intermediate during the catalytic cycle. ${ }^{9}$ Because the $\mathrm{Ni}(\mathrm{I})-\mathrm{CO}$ species is the primary subject of this paper, we illustrate only the upper "CO-first" branch (top panel).

Two competing ACS mechanisms that differ in the oxidation state of the $\mathrm{Ni}_{\mathrm{p}}$ have been proposed. The "paramagnetic mechanism" proposes that $\mathrm{Ni}_{\mathrm{p}}(\mathrm{I})$ and $\mathrm{Ni}(\mathrm{I})-\mathrm{CO}$ are central 
intermediates (Figure 2, top panel) ${ }^{10}$ while the "diamagnetic mechanism" (not shown) proposes a $\mathrm{Ni}(0)$ active catalyst with $\mathrm{Ni}(0)-\mathrm{CO}$ and methyl-Ni(II) [without the paramagnetic methyl-Ni(III)] intermediates. ${ }^{11}$

The so-called "paramagnetic mechanism" proposes paramagnetic species as key intermediates, e.g., $\mathrm{Ni}(\mathrm{I})$ and $\mathrm{Ni}(\mathrm{I})-\mathrm{CO}$. The paramagnetic mechanism is supported by significant kinetic and spectroscopic evidence. For example, when ACS is exposed to CO under reducing conditions, the $\mathrm{EPR}$ active $\mathrm{NiFeC}$ species forms at catalytically relevant rates, and upon reaction with the methylated CFeSP, this species also decays at kinetically competent rates. ${ }^{12-14}$ Furthermore, stopped-flow infrared studies coupled with freeze quench EPR experiments show that reaction of ACS with $\mathrm{CO}$ generates the $\mathrm{Ni}(\mathrm{I})-\mathrm{CO}$ intermediate and that this is the only carbonylated species that develops at catalytically competent rates. ${ }^{14}$ In addition, evidence that supports the proposed internal electron transfer step shown in Figure 2 has been found. ${ }^{15}$ Besides the $\mathrm{NiFeC}$ species, the $\mathrm{Ni}(\mathrm{I})$ intermediate to which $\mathrm{CO}$ binds has been trapped and identified by photolysis followed by EPR and infrared spectroscopic studies. ${ }^{16}$ This $\mathrm{Ni}(\mathrm{I})$ species exhibits an EPR spectrum with $g$ values of $2.56,2.10$, and 2.01 and has an extremely low $(1 \mathrm{~kJ} / \mathrm{mol})$ barrier for recombination with CO. ${ }^{16}$ Thus, when carbonylation is the first step in the ACS mechanism, the involvement of $\mathrm{Ni}(\mathrm{I})$ and the $\mathrm{NiFeC}$ species as catalytic intermediates is well-substantiated. On the basis of the random nature of the methylation and carbonylation steps in the ACS mechanism, ${ }^{9}$ the same $\mathrm{Ni}(\mathrm{I})$ catalyst that has been shown to form the $\mathrm{Ni}(\mathrm{I})-\mathrm{CO}$ intermediate ${ }^{16}$ would be expected to be involved in methylation.

In the diamagnetic mechanism,,${ }^{17}$ the $\mathrm{NiFeC}$ species is viewed as an inhibited state and a $\mathrm{Ni}(0)$ state is proposed to be catalytically relevant. ${ }^{11,18}$ Gencic and Grahame suggested that the active intermediate is a spin-coupled $[4 \mathrm{Fe}-4 \mathrm{~S}]^{+}$cluster linked to a $\mathrm{Ni}(\mathrm{I})$ site, ${ }^{19}$ evidence for which has been provided by Mossbauer spectroscopy. ${ }^{20}$ Regardless, a Ni(0) state in ACS has never been detected, and the spin-coupled species has not been observed to have any catalytic relevance.

Because $\mathrm{CO}$ and the methyl group bind in a random order to $\mathrm{ACS},{ }^{21}$ either the $\mathrm{Ni}-\mathrm{CO}$ intermediate or the methyl-Ni intermediate can serve as the first intermediate in the ACScatalyzed reaction, allowing one to trap and characterize either the metal-CO or the methylmetal adduct. The methyl group is transferred to ACS from another organometallic intermediate, methyl-cob(III)alamin, bound to a corrinoid iron-sulfur protein (CFeSP). ${ }^{22,23}$

In 1985, when this organometallic hypothesis was proposed, ${ }^{1}$ it was not known that ACS activity (or CO binding) was associated with any metal other than $\mathrm{Ni}$, an association based on the observation of an EPR signal (resulting from the species when the enzyme was incubated with $\mathrm{CO}$ ) that exhibited hyperfine broadening from isotopic substitution with ${ }^{61} \mathrm{Ni}$ and ${ }^{13} \mathrm{CO} .{ }^{24,25}$ The ACS active site was later shown to contain an iron-sulfur cluster on which significant unpaired spin density resides; thus, the $\mathrm{Ni}(\mathrm{I})$ designation assigned to species $\mathbf{2}$ in the $\mathrm{NiFeC}$ species is only a simplification, and formally, a fractional spin should be assigned to the $\mathrm{Ni}$ in that state. ${ }^{26}$ These results begged the question of whether $\mathrm{CO}$ binds to the Ni or Fe subcomponents of the ACS A cluster active site. That question has remained unresolved because the answer requires a method, such as X-ray crystallography, resonance 
Raman, or X-ray absorption spectroscopy (XAS), that can probe and identify the metal ion to which $\mathrm{CO}$ binds. Unfortunately, as described below, various issues, including the inability to obtain sufficiently large amounts of the active $\mathrm{NiFeC}$ species, prevented that definitive characterization. Thus, many papers have been published over the past 30 years in which the original organonickel hypothesis has been reproduced in different semblances, yet direct evidence of the nature of the metal-carbon bond has been lacking.

Besides the unusual nature of this bio-organometallic reaction sequence, CODH/ACS has attracted attention because it plays the key role(s) in the Wood-Ljungdahl pathway of autotrophic $\mathrm{CO}_{2}$ and $\mathrm{CO}$ fixation, a metabolic cycle that is important in the global carbon cycle as a predominant $\mathrm{CO}_{2}$ sink in anaerobic environments ${ }^{27}$ that is being exploited for the biotechnological conversion of waste and greenhouse gases into chemicals. ${ }^{28}$ It is the basis of energy metabolism in acetogenic bacteria, for autotrophic $\mathrm{CO}_{2}$ fixation in acetogenic bacteria and methanogens, and for acetate catabolism by sulfate-reducing bacteria and aceticlastic methanogens. ${ }^{27,29}$ This pathway has also been proposed to have fueled the primordial biochemical reactions required for the origin of life and to have developed from a prebiotic reaction sequence using $\mathrm{H}_{2}$ as the initial electron donor and $\mathrm{CO}_{2}$ as the initial electron acceptor. ${ }^{30}$ Thus, it is crucial to understand the mechanism by which this enzyme generates acetyl-CoA and in particular to define the nature of the proposed organometallic intermediates.

Spectroscopic and kinetic studies have focused on identifying and characterizing the intermediates in the ACS-catalyzed reaction. For example, $\mathrm{CO}$ binds in an end-on fashion to one of the metal sites in the A cluster forming an organometallic EPR detectable metalcarbonyl species in which the unpaired electron is delocalized over the Fe and $\mathrm{Ni}$ centers and the CO subcomponent (labeled the NiFeC species). ${ }^{13,14,26,31-33}$ As described below, the rate constant for formation of the $\mathrm{NiFeC}$ species and its electrochemical properties are consistent with this species being a catalytic intermediate in acetyl-CoA synthesis; ${ }^{13,14,21,32,34,35}$ however, although it has been generally accepted that organometallic species involving $\mathrm{CO}$, methyl, and acetyl groups accumulate at $\mathrm{Ni}_{\mathrm{p}}$, several problems have precluded direct identification of any of the metal-carbon bonds proposed to form during the ACS reaction cycle. CODH/ACS, the only form in which ACS is naturally found, contains a low proportion of the binickel center at the active site, with the $\mathrm{Ni}_{\mathrm{p}}$ subcomponent depleted in $\mathrm{Ni},{ }^{36}$ and often substituted with other metals $(\mathrm{Cu}$ and $\mathrm{Zn}) .{ }^{6,37}$ Furthermore, the presence of two unique $\mathrm{Ni}-\mathrm{Fe}$ clusters and additional $\mathrm{Fe}-\mathrm{S}$ clusters in $\mathrm{CODH} / \mathrm{ACS}$ makes spectroscopic studies, aimed at understanding binding of $\mathrm{CO}$ to the ACS subcomponent, extremely challenging. Thus, it has not been possible to prepare high levels of the fully reconstituted A cluster or to produce sufficient amounts of the carbonylated state, hamstringing any structural characterization of these intermediates. These problems have left the proposal of the organometallic intermediates without a firm structural basis and with a limited understanding of their electronic structure.

We have utilized a previously developed expression system for ACS alone in Escherichia $\mathrm{coll}^{35}$ and in some of the preparations obtained with a nearly fully loaded A cluster, with high levels of the $\mathrm{NiFeC}$ species, according to the nearly stoichiometric development of the EPR signal (termed the "NiFeC signal") associated with the active state of ACS. ${ }^{12-14,21} \mathrm{We}$ 
achieved spin percentages between 30 and $65 \%$ and utilized the protein preparation with a $65 \%$ spin percentage to perform high-resolution Fe and Ni K-edge XAS and EXAFS measurements on the as-isolated protein $\left(\mathrm{A}_{\mathrm{OX}}\right)$, its dithionite-treated form (traditionally and operationally called $\mathrm{A}_{\mathrm{RED}}$ ), and the CO-bound form (with a strong $\mathrm{NiFeC}$ signal, $\mathrm{A}_{\mathrm{NiFeC}}$ ), formed by treating ACS with dithionite and $\mathrm{CO}$. These geometric and electronic structure determination techniques were combined with DFT calculations to unambiguously identify and characterize the organometallic $\mathrm{Ni}_{\mathrm{p}}-\mathrm{CO}$ bond in $\mathrm{A}_{\mathrm{NiFeC}}$. Because XAS is an elementspecific technique with exceptional precision $( \pm 0.02 \AA)$ in measuring metal-ligand bond distances, the Fe and Ni sites can be individually probed at high resolution. Furthermore, any change in the $\mathrm{Fe}$ or $\mathrm{Ni} \mathrm{K}$-edge spectrum is due to a direct perturbation of the geometric and electronic structures at the respective site(s) in ACS. A combination of spectroscopic and DFT computational studies on ACS and model compounds ${ }^{38-41}$ have shown that the bisamidate coordination sphere around $\mathrm{Ni}_{\mathrm{d}}$ stabilizes this site as a diamagnetic square-planar $\mathrm{Ni}(\mathrm{II})$ complex under all catalytic conditions; ${ }^{4}$ thus, the changes in the Ni K-edge XAS data overwhelmingly represent changes at the $\mathrm{Ni}_{\mathrm{p}}$ site.

\section{MATERIALS AND METHODS}

\section{Protein Expression and Purification, Metal Analysis, and EPR Spectroscopy}

The a-subunit was prepared, purified, and Ni-reconstituted under strictly anaerobic conditions at $<1 \mathrm{ppm} \mathrm{O}_{2}$ in a manner similar to that described previously but with several modifications. ${ }^{21}$ The pETACSMTHT plasmid was modified to have a TEV protease cleavage site just before the $\mathrm{C}$-terminal His tag. Upon isolation of the pure protein, the His tag was removed using $1 \mathrm{mM}$ sodium citrate instead of the commonly used EDTA in the protease reaction mixture to prevent any damage to the precious A cluster. Metal reconstitution was achieved by incubating the enzyme with a 6-fold excess of nickel(II) chloride at $45^{\circ} \mathrm{C}$ for 3 days. Excess nickel was removed from the solution by passing the protein $(<1 \mathrm{~mL})$ twice through an anaerobic $8.3 \mathrm{~mL}$ PD-10 desalting column. The volume of protein applied to the column was limited to $1 \mathrm{~mL}$ to achieve adequate separation. The metal content of the samples was analyzed by ICP-OES at the Center for Applied Isotope Studies at the University of Georgia (Athens, GA). Concentrations were determined using the Rose Bengal protein assay using a standard curve prepared against dry ACS. Enzyme activity was determined by performing the acetyl-CoA/CO exchange reaction at $55^{\circ} \mathrm{C}$ in $1 \mathrm{~mL}$ of 270 $\mathrm{mM}$ MES buffer (pH 6.1) containing $2 \mathrm{mM}$ Ti(III) citrate, $0.2 \mathrm{mM}$ methyl viologen, $0.2 \mathrm{mM}$ acetyl-CoA, and $0.03-0.04 \mu \mathrm{Ci}$ of $\left[1-{ }^{14} \mathrm{C}\right]$ acetyl-CoA under an atmosphere of $\mathrm{CO}$, and the data were analyzed as described previously. ${ }^{42}$

EPR samples were prepared in a manner similar to that of the CO-treated XAS samples as described below and transferred to EPR tubes. EPR spectra were recorded at $110 \mathrm{~K}$ under nonsaturating conditions. Spin quantification was performed by comparison with a $1 \mathrm{mM}$ copper(II) standard.

\section{XAS Sample Preparation}

The reconstituted enzyme was buffer exchanged into $50 \mathrm{mM}$ potassium phosphate ( $\mathrm{pH} 7.5$ ) with $100 \mu \mathrm{M}$ DTT. As a glassing agent and to minimize ice crystal formation, glycerol was 
added to a final concentration of $30 \%$. The as-isolated sample was produced directly from this initial preparation. The rest of the preparation was reduced by addition of concentrated sodium dithionite to a final concentration of $3 \mathrm{mM}$. The dithionite-reduced sample was made of this preparation. Some of this protein preparation was purged for $15 \mathrm{~min}$ with ultra-highpurity carbon monoxide that was further purified using an oxygen trap. This CO-purged enzyme was used to prepare the CO-ligated sample. Protein concentrations of the actual samples were determined to be $1.06 \mathrm{mM}$ for ACS as isolated, $1.04 \mathrm{mM}$ for the dithionitereduced form, and $1.07 \mathrm{mM}$ for the CO-bound samples using the Rose Bengal protein assay.

The solution samples $(\sim 80 \mu \mathrm{L})$ were transferred into $1 \mathrm{~mm}$ delrin XAS cells with $70 \mu \mathrm{m}$ Kapton tape windows. The solution samples were immediately frozen after preparation and stored under liquid $\mathrm{N}_{2}$. Each sample holder afforded six fresh sample positions $(1 \mathrm{~mm} \times 4$ $\mathrm{mm}$ beam) for EXAFS measurements. Three each were used to obtain the Ni and Fe XAS data.

\section{EPR Spin Quantitation and Application to EXAFS}

The $\mathrm{Ni}_{\mathrm{p}}$ site in ACS is labile and binds weakly relative to the $\mathrm{Ni}_{\mathrm{d}}$ site as evidenced by XRD data that show the site occupied by $\mathrm{Zn}$ and $\mathrm{Cu}$. The loading of the $\mathrm{Ni}_{\mathrm{p}}$ site is of special concern here, because free $\mathrm{Ni}$ in solution would dilute the signal from the ACS site. The presence of free Ni in ACS was evident in some preparations of ACS tested by EXAFS, which showed some differences in the rising-edge region between $A_{O X}$ and $A_{R E D}$, indicating the reduction of free $\mathrm{Ni}$ in solution. This was further validated by the lack of a statistically significant $\mathrm{Ni}-\mathrm{CO}$ signal in the corresponding $\mathrm{A}_{\mathrm{NiFeC}}$ EXAFS data for these samples. This analysis is predicated on the relative standard redox potentials for free $\mathrm{Ni}(\mathrm{II}) /(0)(-0.257 \mathrm{~V}, \mathrm{pH}$-independent $)$ and dithionite $(-0.46 \mathrm{~V}$ at $\mathrm{pH} 7) .{ }^{43}$ Therefore, dithionite is strong enough to reduce free $\mathrm{Ni}(\mathrm{II})$ to $\mathrm{Ni}(0)$.

EPR spectroscopy was used for spin quantitation of $A_{\mathrm{NiFeC}}$, which revealed 0.65 spin per monomer compared to that of a reference copper complex. The data presented here were measured on a sample with $1.75 \mathrm{Ni}$ atoms per monomer of ACS. The similarity of the XAS data for $A_{O X}$ and $A_{R E D}$ presented in Figure 4 shows that no free Ni is present in the sample used in this analysis. Because the spectroscopic features of $\mathrm{Ni}(0)$ are so dramatically different from those of $\mathrm{Ni}(\mathrm{II})$, the reduction of even a small amount of free Ni would significantly alter the $\mathrm{Ni}$ K-edge XANES. Assuming the tightly bound $\mathrm{Ni}_{\mathrm{d}}$ site is fully occupied, we found the $\mathrm{Ni}_{\mathrm{p}}$ site occupies 0.75 site and thus would lead to at most 0.75 spin in EPR if $100 \%$ of the $\mathrm{Ni}_{\mathrm{p}}$ sites were bound by $\mathrm{CO}$. Thus, the observed 0.65 spin indicates that $\sim 87 \%$ of the $\mathrm{Ni}_{\mathrm{p}}$ sites are CO-bound, which is expected to result in a $37 \% \mathrm{Ni}-\mathrm{C}$ contribution to the EXAFS data. This is approximated to $0.4 \mathrm{Ni}-\mathrm{C}$ in the FEFF fits.

\section{X-ray Absorption Spectroscopic Measurements}

X-ray absorption spectra were recorded at the Stanford Synchrotron Radiation Lightsource (SSRL) on focused 16-pole, $2 \mathrm{~T}$ wiggler side-station beamline 9-3 under standard ring conditions of $3 \mathrm{GeV}$ and $\sim 500 \mathrm{~mA}$. A Si(220) double-crystal monochromator was used for energy selection. A Rh-coated harmonic rejection mirror was used to reject components of higher harmonics. During data collection, the samples were maintained at a constant 
temperature of $\sim 10 \mathrm{~K}$ using an Oxford Instruments CF 1208 liquid helium cryostat. A 100element Ge monolith fluorescence detector from Canberra Industries was employed for the measurement of fluorescence data.

Fe K-Edge Measurements-Fe K-edge XAS data were measured on the as-isolated form $\left(\mathrm{A}_{\mathrm{OX}}\right)$, the dithionite-reduced form $\left(\mathrm{A}_{\mathrm{RED}}\right)$, and the dithionite-reduced form subjected to $\mathrm{CO}$ treatment $\left(\mathrm{A}_{\mathrm{NiFeC}}\right)$ in the fluorescence mode by using soller slits equipped with a $\mathrm{Mn}$ filter in front of the $\mathrm{Ge}$ detector and using an $\mathrm{Fe}$ foil for energy calibration. The first inflection point of the foil spectrum was fixed at $7111.2 \mathrm{eV}$. The samples were monitored for photoreduction and showed no signs of change during the course of data collection. Fe Kedge EXAFS data were measured up to $k=17 \AA^{-1}$. The data presented here are eight-scan average spectra, collected over three fresh sample positions for each of the samples.

Ni K-Edge Measurements-Ni K-edge XAS data were measured on $\mathrm{A}_{\mathrm{OX}}, \mathrm{A}_{\mathrm{RED}}$, and $\mathrm{A}_{\mathrm{NiFeC}}$ samples in fluorescence mode by using soller slits equipped with a Co filter in front of the $\mathrm{Ge}$ detector and using a $\mathrm{Ni}$ foil for energy calibration. The first inflection point of the foil spectrum was fixed at $8331.6 \mathrm{eV}$. The samples were monitored for photoreduction, and no sign of photodamage or $\mathrm{Ni}-\mathrm{CO}$ bond cleavage was observed during the course of data collection. Ni K-edge EXAFS data were measured up to $k=19 \AA^{-1}$. The data presented here are 12-scan average spectra, collected over three fresh sample positions for each of the samples.

XAS Data Reduction-Data presented in this study were processed by fitting a secondorder polynomial to the pre-edge region and subtracting this from the entire spectrum as background in PySpline. ${ }^{44} \mathrm{~A}$ four-region spline with orders of 2, 3, 3, and 3 was used for both the $\mathrm{Ni}$ and $\mathrm{Fe}$ data sets to model the smoothly decaying postedge region. Theoretical EXAFS signals $\chi(k)$ were calculated by using FEFF (macintosh version 7) ${ }^{45,46}$ on the active site structure derived from the crystal structure of ACS (Protein Data Bank entry 1RU3). ${ }^{7}$ For the Fe EXAFS, the $\mathrm{Fe}$ atom bridging to $\mathrm{Ni}_{\mathrm{p}}$ via a cysteine thiolate was chosen as the absorbing atom to generate phase and amplitude parameters. For the Ni EXAFS, structural models were generated for the different putative forms of $\mathrm{Ni}_{\mathrm{p}}$ and $\mathrm{Ni}_{\mathrm{d}}$ sites. The molecule editing software Avogadro was used to modify the structural parameters obtained from the crystal structure. DFT geometry-optimized structures were also used to generate phase and amplitude parameters for the CO-bound form of ACS $\left(\mathrm{A}_{\mathrm{NiFeC}}\right)$. Theoretical models were fit to the data using EXAFSPAK ${ }^{47}$ The structural parameters varied during the fitting process were the bond distance $(R)$ and bond variance $\sigma^{2}$, which is related to the Debye-Waller factor resulting from thermal motion, and static disorder of the absorbing and scattering atoms. The nonstructural parameter $\Delta E_{0}$ (the energy at which $k=0$ ) was also allowed to vary but was restricted to a common value for every component in a given fit. Coordination numbers were systematically varied in the course of the fit but were fixed within a given fit.

Statistical Evaluation of EXAFS Fits-The presence of a $\mathrm{Ni}-\mathrm{C}$ component was statistically tested as follows. Two fits were performed: one without any $\mathrm{Ni}-\mathrm{CO}$ components and one assuming a $0.4 \mathrm{Ni}-\mathrm{CO}$ contribution to the EXAFS data (Table 2). The reduced $\chi^{2}$ error values (which normalize the error function for the additional fit parameters, i.e., arising 
from the inclusion of single and multiple scattering components for the $\mathrm{Ni}-\mathrm{CO}$ intermediate) are listed and are lower for the fit that includes the $\mathrm{Ni}-\mathrm{CO}$ components and indicate that fit 2 is statistically better. A Hamilton $F$ test was performed with a probability hypothesis of $>90 \% .{ }^{48}$ In addition to the statistical evaluation, a strong indicator of the presence of a Ni-C component is the behavior of the $\mathrm{Ni}-\mathrm{N} \sigma^{2}$ value. In the fit without the $\mathrm{Ni}-\mathrm{C}$ component (fit 1 ), the $\sigma^{2}$ for the $\mathrm{Ni}-\mathrm{N}$ component is 2 -fold higher than in fit 2, which includes the $\mathrm{Ni}-\mathrm{CO}$ components (Table 2). The $\mathrm{Ni}-\mathrm{N} \sigma^{2}$ of $\mathrm{A}_{\mathrm{NiFeC}}$ in fit 2 is similar to that in $\mathrm{A}_{\mathrm{OX}}$ and $\mathrm{A}_{\mathrm{RED}}$, consistent with the idea that bonding in $\mathrm{Ni}_{\mathrm{d}}$ does not change significantly upon reduction and $\mathrm{CO}$ binding.

\section{Density Functional Theory Calculations}

Gradient-corrected spin unrestricted DFT calculations were performed using the ORCA ${ }^{49,50}$ package (ORCA version 3.03). ${ }^{51}$ The BP86 local functional and the following basis sets were employed for the calculations: Ahlrich's all electron triple- $\zeta$ basis set TZVPP with three polarization functions on Ni, TZVP on all other atoms. ${ }^{52}$ Tight convergence criteria were imposed on all calculations. Calculations were performed in a dielectric continuum using the conductor-like screening model (COSMO) $)^{53}$ with a dielectric constant of 7 . Starting guess geometries were obtained from the 1RU3 crystal structure and modified appropriately for the $\mathrm{A}_{\mathrm{OX}}, \mathrm{A}_{\mathrm{RED}}$, and $\mathrm{A}_{\mathrm{NiFeC}}$ states. The $\mathrm{Ca}$ atoms of six protein amino acid ligands to the cluster, marked with a star in Figure 6, for the sake of clarity were fixed for all calculations. These include the four cysteinates bound to the $\mathrm{Fe}-\mathrm{S}$ clusters and one each from the phenylalanine and serine residues adjacent to the cysteinates bound to $\mathrm{Ni}_{\mathrm{p}}$ and $\mathrm{Ni}_{\mathrm{d}}$. Tetrahedral and square-planar coordination was explored for the $\mathrm{Ni}_{\mathrm{p}}$ site in all states. For $\mathrm{A}_{\mathrm{OX}}$, a three- and four-coordinate $\mathrm{Ni}_{\mathrm{p}}$ site was tested. A water molecule was added at the $\mathrm{Ni}_{\mathrm{p}}$ open site in $\mathrm{A}_{\mathrm{OX}}$ to geometry optimize a four-coordinate $\mathrm{Ni}_{\mathrm{p}}$ site. For $\mathrm{A}_{\mathrm{OX}}$, optimizations without a fourth ligand led to unlikely perturbation of the active site; for example, the $\mathrm{Ni}_{\mathrm{p}}$ site coordinated to the closed sulfide of the $\mathrm{Fe}-\mathrm{S}$ cluster formed a $\mathrm{Ni}-\mathrm{S}-\mathrm{Fe}$ bond. This is consistent with previous reports in which a geometric constraint on the $\mathrm{Ni}-$ sulfide distance had to be imposed to theoretically evaluate the $\mathrm{A}_{\mathrm{RED}}$ state. ${ }^{54}$ The fourcoordinate structure was optimized to a square-planar geometry, irrespective of the starting geometry (see Figure 6). Although it is likely that the four-coordinate $\mathrm{Ni}_{\mathrm{p}}$ in $\mathrm{A}_{\mathrm{OX}}$ would lose the water ligand upon reduction, DFT optimizations of $A_{\text {RED }}$ with a four- or threecoordinate site invariably led to Ni-sulfide ligation (as described above and as observed previously). ${ }^{54}$ A representative input file is included in the Supporting Information, showing strategies employed for the convergence of pathological systems such as $\mathrm{Fe}-\mathrm{S}$ clusters (the pathology being the large number of SCF convergence cycles, increasing the number of Fock matrices for the DIIS extrapolation and increasing the rebuilding frequency of the full Fock matrices). All calculations were checked for proper spin convergence of the $[4 \mathrm{Fe}-4 \mathrm{~S}]^{2+}$ cluster and to achieve the true broken symmetry ground state. Time-dependent DFT (TDDFT) calculations were performed with the electronic structure program ORCA to calculate the energies and intensities of the Ni K pre-edges. The tight convergence criterion was imposed on all calculations. The same functional and basis sets that were used for the geometry optimizations were used for the TD-DFT calculations. The calculated energies and intensities were Gaussian-broadened with half-widths of $1.5 \mathrm{eV}$ to account for core-hole lifetime and instrument resolution. The calculated pre-edge energy positions were linearly 
scaled to match the experimental spectra. This is generally the case with core level TD-DFT calculations because DFT does not describe core potentials accurately, resulting in the core levels having energies that are too high relative to those of the valence levels.

\section{RESULTS AND DISCUSSION}

\section{Generation of ACS Containing High Levels of $\mathrm{Ni}_{p}$ Occupancy, Activity, and Spin Concentration}

As described above, with slight modification of a previously published method, ${ }^{21}$ recombinantly expressed ACS was prepared, purified, and Ni-reconstituted to yield a nearly metal-replete sample exhibiting high levels of activity and spin concentrations. Generating a highly active sample is mandatory for detection of the organometallic intermediates because the bound $\mathrm{CO}$ is a relatively low intensity scatterer and because, even if the A cluster is $100 \%$ loaded in both $\mathrm{Ni}_{\mathrm{p}}$ and $\mathrm{Ni}_{\mathrm{d}}$ sites and no extraneous $\mathrm{Ni}$ is present, the maximal amount of $\mathrm{Ni}_{\mathrm{p}}-\mathrm{CO}$ will be $50 \%$ of the total $\mathrm{Ni}$. Thus, our goal was to obtain a sample of ACS containing more than $\sim 60 \%$ bound carbonyl, as assayed by the EPR spin intensity of the $\mathrm{NiFeC}$ signal. Generating such a sample has been an ongoing effort of this laboratory for decades.

The CO-treated enzyme used in the XAS experiments exhibited a large amount of FeNiC EPR signal intensity $(0.65 \mathrm{spin} / \mathrm{mol})$. This is much higher than the spin intensities reported for XAS samples reported earlier (Table S2), which were in the range of $0.06-0.25 \mathrm{spin} / \mathrm{mol}$. Our high spin intensity value is congruent with the metal content, which was determined to be $4.2 \mathrm{Fe}, 1.8 \mathrm{Ni}, 0.05 \mathrm{Zn}$, and $0.01 \mathrm{Cu}$ per monomeric unit of ACS, with all values having a $2-4 \%$ standard deviation. Furthermore, the ACS specific activity, measured by the acetyl$\mathrm{CoA} / \mathrm{CO}$ exchange reaction, was very high, i.e., $4.2 \pm 0.2$ units $/ \mathrm{mg}$ at $55^{\circ} \mathrm{C}$ and $\mathrm{pH} 6.1$. As shown in Table S2, previous EXAFS experiments were performed with $M$. thermoacetica ACS samples exhibiting $>10$-fold lower specific activities $\left(0.18-0.36 \mu \mathrm{mol} \mathrm{min}{ }^{-1} \mathrm{mg}^{-1}\right)$. The highest previously reported value for an XAS sample was that of Carboxydothermus hydrogenoformans ACS, $2.4 \mu \mathrm{mol} \mathrm{min}{ }^{-1} \mathrm{mg}^{-1}$ (measured at $70{ }^{\circ} \mathrm{C}$ ). The specific activity of 4.2 units $/ \mathrm{mg}$ for a sample with 0.65 spin of $\mathrm{NiFeC}$ signal is consistent with that (3.2 units/mg with 0.5 spin per ACS monomer) exhibited by recent samples from our laboratory using a similar ACS preparation method. ${ }^{15}$ As described above (Materials and Methods), the observed 0.65 spin indicates that $\sim 87 \%$ of the $\mathrm{Ni}_{\mathrm{p}}$ sites are CO-bound, which is expected to result in a $37 \% \mathrm{Ni}-\mathrm{C}$ contribution to the EXAFS data. This is approximated to $0.4 \mathrm{Ni}-\mathrm{C}$ in the FEFF fits (below).

\section{The [4Fe-4S] Subcomponent of the A Cluster Is Similar in Its Oxidized, Dithionite-Reduced, and CO-Treated Forms}

Electronic and geometric characterization of the $[4 \mathrm{Fe}-4 \mathrm{~S}]$ part of the A cluster was performed on the $\mathrm{A}_{\mathrm{OX}}$ (as-isolated), $\mathrm{A}_{\mathrm{RED}}$ (dithionite-treated), and $\mathrm{A}_{\mathrm{NiFeC}}$ (dithionite- and CO-treated) states using Fe K-edge and EXAFS studies. The XAS data (Figure 3A) for these forms are very similar to data published for $[4 \mathrm{Fe}-4 \mathrm{~S}]^{2+}$ clusters, ${ }^{55,56}$ with no significant shift in the rising-edge energy positions among the three states. This similarity in the edge data is mirrored in the Fe K-edge EXAFS data (Figure 3B) and the comparison of their 
corresponding fits (Figure S1 and Table S1). All data sets are consistent with four Fe-S components at $2.28 \AA$ and three $\mathrm{Fe}-\mathrm{Fe}$ components at $2.7 \AA$, further confirming the $[4 \mathrm{Fe}-4 \mathrm{~S}]^{2+}$ nature of the $[4 \mathrm{Fe}-4 \mathrm{~S}]$ cluster in all three states. Similarity in the EXAFS data also indicates that (a) $\mathrm{CO}$ does not bind at an $\mathrm{Fe}$ site and (b) no structural distortion of the cluster occurs in the process of $\mathrm{CO}$ binding. No evidence of the presence of a $\mathrm{Fe}-\mathrm{Ni}_{\mathrm{p}}$ contribution to the EXAFS data was found, which is expected because only one of the $\mathrm{Fe}$ atoms is bridged to the $\mathrm{Ni}_{\mathrm{p}}$ center (via the thiolate sulfur). Thus, these spectroscopic results reveal that the $[4 \mathrm{Fe}-4 \mathrm{~S}]^{2+}$ site in the A cluster remains in the same oxidation state, with minimal change in the electronic structure upon reduction of $A_{O X}$ to $A_{R E D}$ and conversion of $A_{R E D}$ to $A_{\mathrm{NiFeC}}$ upon treatment with $\mathrm{CO}$. These data also indicate that the A cluster is near fully replete with $\mathrm{Ni}$, because, as indicated earlier by Mossbauer and EPR studies of recombinant $\mathrm{ACS},{ }^{18} \mathrm{a} \mathrm{Ni}_{\mathrm{p}}$-deficient A cluster results in reduction of the $[4 \mathrm{Fe}-4 \mathrm{~S}]$ cluster by dithionite.

\section{Geometric and Electronic Structures of the Oxidized and Dithionite-Reduced States of the A Cluster}

The Ni centers in the $\mathrm{A}_{\mathrm{OX}}$ and $\mathrm{A}_{\mathrm{RED}}$ A cluster were studied using Ni K-edge XAS (Figure 4A) and EXAFS (Figure 4B). The weak pre-edge feature at $8331.9 \mathrm{eV}$ that occurs before the onset of the rising edge (Figure $4 \mathrm{~A}$, inset) is attributed to the $1 \mathrm{~s} \rightarrow 3 \mathrm{~d}$ transition indicating similar ligand-field strengths and oxidation states of the Ni centers in $A_{O X}$ and $A_{R E D}$. Furthermore, a comparison of the rising-edge region in both $\mathrm{A}_{\mathrm{OX}}$ and $\mathrm{A}_{\mathrm{RED}}$ shows a feature at $\sim 8335 \mathrm{eV}$ that is attributed to structural and electronic processes (four-body multiple scattering and formally forbidden shakedown transitions), 57,58 which are enhanced for centrosymmetric square-planar systems but are attenuated when geometries diverge from the square-planar limit. The similarities in both energy position and intensity of this feature in $\mathrm{A}_{\mathrm{OX}}$ and $\mathrm{A}_{\mathrm{RED}}$ indicates that the structure and electronics at the Ni centers remain unperturbed upon dithionite treatment of $\mathrm{A}_{\mathrm{OX}}$.

This similarity is also reflected in the nearly identical Ni K-edge EXAFS and Fourier transforms of $A_{O X}$ and $A_{R E D}$ (Figure 4B). FEFF fits to the EXAFS data were performed to obtain quantitative local structure information. Because EXAFS data are an average of the $\mathrm{Ni}_{\mathrm{p}}$ and $\mathrm{Ni}_{\mathrm{d}}$ sites, where appropriate, the fits were performed with partial coordination numbers. The crystal structure (Figure 2) shows the $\mathrm{Ni}_{\mathrm{d}}$ site to be square-planar with $\mathrm{NiN}_{2} \mathrm{~S}_{2}$ ligation, while $\mathrm{Ni}_{\mathrm{p}}$ can assume either a trigonal $\left(\mathrm{NiS}_{3}\right)$ or a square-planar $\left(\mathrm{NiS}_{3} \mathrm{O}\right)$ coordination. ${ }^{6,8}$ The best fit to $\mathrm{A}_{\mathrm{OX}}$ was obtained with one Ni-N group at $1.90 \AA$, $2.5 \mathrm{Ni}-\mathrm{S}$ groups at $2.18 \AA$, and $0.5 \mathrm{Ni}-\mathrm{Fe} / \mathrm{Ni}$ group at $2.95 \AA$ (Figure S2A and Table 1). Note that EXAFS cannot differentiate between Fe and Ni backscattering contributions, especially when the contributions are weak and the backscatteres are similar distances from the absorbing atom. Therefore, the contribution at $2.95 \AA$ is labeled as $0.5 \mathrm{Ni}-\mathrm{Fe} / \mathrm{Ni}$, suggesting that it could arise from a $\mathrm{Ni}$ or $\mathrm{Fe}$ backscatterer. Hereafter, this contribution is termed the Ni-metal contribution to emphasize the limitation of EXAFS. Contrary to previous results, ${ }^{7}$ no evidence of a weak $\mathrm{Ni}-\mathrm{O}$ interaction (coordinating water molecule) was found; however, it is anticipated that any weak $\mathrm{Ni}-\mathrm{O}$ interaction (contributing $0.5 \mathrm{Ni}-\mathrm{O}$ group to the total EXAFS), if present, would be obfuscated by the intense $2.5 \mathrm{Ni}-\mathrm{S}$ group contributions at 2.18 $\AA$. The EXAFS fit for $A_{\text {RED }}$ (Figure S2B and Table 1) produces bond distances identical to 
those in $\mathrm{A}_{\mathrm{OX}}$, suggesting nearly identical geometries for the Ni centers in these states. The somewhat lower Ni-metal coordination (Table 1), which indicates the difference in the $\mathrm{Ni}-$ $\mathrm{Ni}$ and $\mathrm{Ni}-\mathrm{Fe}$ distance, is consistent with all previous EXAFS ${ }^{59-61}$ and X-ray crystallographic ${ }^{6}$ analysis of CODH/ACS and indicates that $\mathrm{Ni}_{\mathrm{p}}$ can assume two conformations. Thus, the EXAFS data show a $\mathrm{Ni}_{\mathrm{p}} \mathrm{S}_{3}$ with an average $\mathrm{Ni}-\mathrm{S}$ bond length of $2.18 \AA$ and a $\mathrm{Ni}_{\mathrm{d}} \mathrm{S}_{2} \mathrm{~N}_{2}$ with an average Ni-S bond length of $2.18 \AA$ and a $\mathrm{Ni}-\mathrm{N}$ bond length of $1.90 \AA$ for both $\mathrm{A}_{\mathrm{OX}}$ and $\mathrm{A}_{\mathrm{RED}}$. These values are in excellent agreement with the proposed geometries of $\mathrm{Ni}_{\mathrm{p}}$ and $\mathrm{Ni}_{\mathrm{d}}$ sites and agree well with the crystallography data (Figure 2).

In summary, the similarities among the Fe and Ni XAS and EXAFS data for $\mathrm{A}_{\mathrm{OX}}$ and $\mathrm{A}_{\mathrm{RED}}$ indicate that there is no observable structural or electronic change upon treatment of ACS with dithionite. This is consistent with previous studies showing that none of the metal sites in $\mathrm{A}_{\mathrm{OX}}$ can be reduced by dithionite alone, ${ }^{60}$ suggesting that the operational $\mathrm{A}_{\mathrm{RED}}$ designation for the dithionite-treated protein is incorrect. The XAS and EXAFS results also provide important information about the recalcitrance of the fully Ni loaded A cluster to reduction by dithionite $\left(E_{0}{ }^{\prime}=-660 \mathrm{mV}\right.$ vs the normal hydrogen electrode $\left.{ }^{62}\right)$. The only published example of trapping and characterizing the one-electron-reduced " $\mathrm{A}_{\mathrm{RED}}$ " state to which $\mathrm{CO}$ binds involved photolysis of $\mathrm{CO}$ from the $\mathrm{A}_{\mathrm{NiFeC}}$ state. ${ }^{35}$ We refer to that state here as $A_{R E D} *$. This $A_{R E D} *$ species is a metastable Ni(I) state that was shown by EPR and IR studies to rapidly recombine with $\mathrm{CO}$ in a temperature-dependent manner to regenerate $\mathrm{A}_{\mathrm{NiFeC}}$. Thus, Figure 2 shows the equilibrium to heavily favor the $\mathrm{Ni}(\mathrm{II})-\mathrm{A}_{\mathrm{OX}}$ form of the $\mathrm{A}$ cluster in the absence of $\mathrm{CO}$, which kinetically traps and stabilizes the $\mathrm{Ni}(\mathrm{I})$ state as $\mathrm{A}_{\mathrm{NiFeC}} \cdot{ }^{35}$

\section{The CO-Bound Intermediate on ACS Has a Nip $-\mathrm{CO}$ Bond}

We used EPR spectroscopy to follow conversion of $A_{R E D}$ to $A_{N i F e C}$ by treatment of ACS with $\mathrm{CO}$ and dithionite under anaerobic conditions. Normalization of the spectrum with protein and $\mathrm{Ni}$ concentrations showed a high level of accumulation ( $87 \%$ of available $\mathrm{Ni}_{\mathrm{p}}$ sites) of the well-characterized NiFeC signal with $g$ values of 2.074 and 2.028 (Figure S3). In comparing the $\mathrm{Ni} \mathrm{K}$-edge XAS spectra of $\mathrm{A}_{\mathrm{NiFeC}}$ (Figure 5A) to that of $\mathrm{A}_{\mathrm{RED}}$ (reproduced from Figure 4A), we find there are significant changes in the pre-edge, in the rising edge, and near the white-line maxima of the spectra. The rising-edge feature in $\mathrm{A}_{\mathrm{NiFeC}}$ occurs at $8335.2 \mathrm{eV}$ and is attenuated relative to that in $\mathrm{A}_{\mathrm{RED}}$, indicating that the $\mathrm{Ni}_{\mathrm{p}}$ site deviates from a square-planar geometry in $\mathrm{A}_{\mathrm{RED}}$ to a tetrahedral geometry in $\mathrm{A}_{\mathrm{NiFeC}}\left(\mathrm{as} \mathrm{Ni}_{\mathrm{d}}\right.$ remains unchanged), The pre-edge feature in $\mathrm{A}_{\mathrm{NiFeC}}$ shifts to lower energies, and its secondderivative spectrum (Figure 5A, inset) shows the presence of two pre-edge features (at 8330.9 and $8331.7 \mathrm{eV}$ ). The energy of the higher-energy pre-edge feature (at $8331.7 \mathrm{eV}$ ) is similar to that of the single pre-edge feature present in $A_{R E D}$ and $A_{O X}$ (see Figure $4 A$ ), suggesting that this feature in $\mathrm{A}_{\mathrm{NiFeC}}$ derives from $\mathrm{Ni}_{\mathrm{d}}$, which is unchanged in these three forms of the enzyme. ${ }^{57,63}$ Thus, the lower-energy pre-edge feature at $8330.9 \mathrm{eV}$ is attributed to the $1 \mathrm{~s} \rightarrow 3 \mathrm{~d}$ transition of $\mathrm{Ni}_{\mathrm{p}}$. Finally, the white-line region between 8340 and $8360 \mathrm{eV}$ is different for $\mathrm{A}_{\mathrm{NiFeC}}$ and $\mathrm{A}_{\mathrm{RED}}$. Such changes are due to a change in geometry around the $\mathrm{Ni}$ center and suggest a perturbation in site geometry upon $\mathrm{CO}$ binding. Thus, the Ni K-edge data of $\mathrm{A}_{\mathrm{OX}}, \mathrm{A}_{\mathrm{RED}}$, and $\mathrm{A}_{\mathrm{NiFeC}}$ unambiguously support $\mathrm{CO}$ binding at the $\mathrm{Ni}_{\mathrm{p}}$ site. 
Interestingly, despite the clear spectral changes that occur upon $\mathrm{CO}$ binding, the Ni K-edge inflection point (typically indicative of a change in oxidation state) does not shift significantly among $\mathrm{A}_{\mathrm{OX}}, \mathrm{A}_{\mathrm{RED}}$, and $\mathrm{A}_{\mathrm{NiFeC}}$. The reason for these small changes in the $\mathrm{Ni}$ edge spectra upon conversion to $\mathrm{A}_{\mathrm{NiFeC}}$ is that reduction can occur at only $\mathrm{Ni}_{\mathrm{p}}$, which represents only half of the probed $\mathrm{Ni}$ sites. In addition, the presence of five other heavy atom backscatterers in the A cluster tends to broaden edge features and obfuscate changes due to $Z_{\text {eff. }}$ Furthermore, ENDOR, EPR, and Mössbauer studies show that the unpaired electron in the $\mathrm{Ni}-\mathrm{CO}$ state is delocalized among the $\mathrm{Ni}, \mathrm{CO}$, and [4Fe4S] cluster. ${ }^{18,26,31,33}$ Thus, although the bond is between $\mathrm{Ni}$ and $\mathrm{C}$ and we formally identify the species as $\mathrm{Ni}_{\mathrm{p}}(\mathrm{I})-\mathrm{CO}$, only part of the unpaired electron spin density is on $\mathrm{Ni}_{\mathrm{p}}{ }^{26}$ The lack of edge energy shifts in either Fe or Ni K-edge XAS data, the similarity of the Fe and Ni EXAFS, the results of the DFT and TD-DFT calculations (below), and the lack of any significant changes in the UVvisible spectrum upon conversion of $\mathrm{A}_{\mathrm{OX}}$ to $\mathrm{A}_{\mathrm{NiFeC}}$ all demonstrate that the average effect of reduction on each of the $\mathrm{Fe}$ atoms in the $[4 \mathrm{Fe}-4 \mathrm{~S}]^{2+}$ cluster or on the $\mathrm{Ni}_{\mathrm{p}}$ site is small and further support the idea that $\mathrm{A}_{\mathrm{NiFeC}}$ is a highly delocalized spin system. This is also supported by the Mulliken population analysis of the valence orbitals (see Table S3 and the DFT section) involved in the Ni K-pre-edge transitions.

The Ni and Fe XAS and EXAFS data are relevant to a controversy about the intermediacy of $\mathrm{A}_{\mathrm{NiFeC}}$ (summarized in ref 4) versus a two-electron-reduced species formally identified as $\mathrm{Ni}(0)^{11,64}$ in the ACS catalytic cycle. The small differences in the Ni-edge and EXAFS spectra among $A_{O X}, A_{R E D}$, and $A_{\mathrm{NiFeC}}$ support one-electron reduction to form a highly delocalized $\mathrm{A}_{\mathrm{NiFeC}}$ rather than a formally two-electron reduced A cluster with a $\mathrm{Ni}(0)$ or $\mathrm{Ni}(\mathrm{I}) /[4 \mathrm{Fe}-4 \mathrm{~S}]^{+}$electronic state. Furthermore, a $\mathrm{Ni}(0)$ state in ACS has never been reported, and two-electron reduction of $\mathrm{Ni}(\mathrm{II})$ to $\mathrm{Ni}(0)$ in the highly electropositive environment formed by $\mathrm{Ni}_{\mathrm{d}}(\mathrm{II})$ and $[4 \mathrm{Fe}-4 \mathrm{~S}]^{2+}$ would be extremely difficult given that the redox potential for reductive activation of ACS to the $\mathrm{Ni}_{\mathrm{p}}(\mathrm{I})-\mathrm{CO}$ state is already very negative, approximately -500 to $-540 \mathrm{mV}^{65,66}$

The Ni K-edge EXAFS data (and the non-phase-shift-corrected Fourier transforms) for the $\mathrm{A}_{\mathrm{RED}}$ and $\mathrm{A}_{\mathrm{NiFeC}}$ states exhibit large differences in the phase and amplitude parameters (Figure 5B). In the FT data of $\mathrm{A}_{\mathrm{NiFeC}}$, both the first-shell ( $R^{\prime}$ between 1.2 and $1.8 \AA$ ) intensity and the second-shell ( $R^{\prime}$ between 1.9 and $3.0 \AA$ ) $R^{\prime}$ values decrease, resulting in two main features compared to a single feature in the second shell of $A_{R E D}$. FEFF fits were performed on the EXAFS data for $\mathrm{A}_{\mathrm{NiFeC}}$ with several structural models, including that obtained from DFT geometry optimization. The best fits to the data were consistent with a first shell composed of $0.4 \mathrm{Ni}-\mathrm{C}$ group at $1.77 \AA, 1 \mathrm{Ni}-\mathrm{N}$ group at $1.89 \AA, 2 \mathrm{Ni}-\mathrm{S}$ groups at $2.22 \AA$, and $0.5 \mathrm{Ni}-\mathrm{S}$ group at $2.33 \AA$. A $0.5 \mathrm{Ni}-$ metal component was found at $2.78 \AA$ (Figure $\mathrm{S} 4$ and Table 2). It is important to note that a $\mathrm{Ni}-\mathrm{C}-\mathrm{O}$ multiple-scattering contribution had to be included in the fit to obtain reasonable Debye-Waller factors. This suggests a linear (or nearly linear) $\mathrm{Ni}-\mathrm{C}-\mathrm{O}$ arrangement upon $\mathrm{CO}$ binding, because a bent $\mathrm{CO}$ would not significantly contribute to the EXAFS data. This is supported by the DFT geometry optimizations performed on $\mathrm{A}_{\mathrm{NiFeC}}$, which shows an $\mathrm{Fe}-\mathrm{C}-\mathrm{O}$ angle of $177^{\circ}$ (see the next section and Figure 6). Together, the Ni K-edge and EXAFS data unambiguously show an organometallic $\mathrm{Ni}-\mathrm{CO}$ bond in $\mathrm{A}_{\mathrm{NiFeC}}$ and provide the first structural evidence of binding of $\mathrm{CO}$ to $\mathrm{Ni}_{\mathrm{p}}$. Furthermore, although the data are consistent with the assumption that 
backbone amide $(\mathrm{N})-\mathrm{Ni}_{\mathrm{d}}$ interaction remains virtually unchanged between $\mathrm{A}_{\mathrm{RED}}$ and $\mathrm{A}_{\mathrm{NiFeC}}$ (no change in the Ni-N component), a significant elongation of the $\mathrm{Ni}-\mathrm{S}$ distances is observed. The single $2.5 \mathrm{Ni}-\mathrm{S}$ group contributions at $2.18 \AA$ in $\mathrm{A}_{\mathrm{RED}}$ can now be separated into a shorter contribution from $2.0 \mathrm{Ni}-\mathrm{S}$ groups at $2.22 \AA$ and a longer contribution from $0.5 \mathrm{Ni}-\mathrm{S}$ group at $2.33 \AA$ in $\mathrm{A}_{\mathrm{NiFeC}}$. This indicates that $\mathrm{CO}$ binding results in elongation of the Ni-S contribution in general and in particular at the $\mathrm{Ni}_{\mathrm{p}}$ site. The EXAFS data also indicate that the $\mathrm{Ni}$-metal (see above) bond is $\sim 0.2 \AA$ shorter than that in the $\mathrm{A}_{\mathrm{OX}}$ and $\mathrm{A}_{\mathrm{RED}}$ states.

Ni K-edge XANES and EXAFS have previously been exploited to study the geometric structure of the active sites of CODH and ACS. While EXAFS data have been quantitatively fit using FEFF (multiple-scattering methodology), the published XANES analysis has been very qualitative, mostly devoted to estimating the deviation of the $\mathrm{Ni}$ active site from a square-planar limit (and toward a tetrahedral limit) or in following the variability in the edge shape and energy position depending on ligand type.$^{67}$ Furthermore, EXAFS analyses ${ }^{60,61,68}$ published prior to the crystal structures described in 2002 and 2003 5,6 were based on ACS containing a single Ni center at the ACS active site and therefore (as later revealed) had largely incorrect interpretations of the Ni centers. For example, a 1998 study reveals that upon removal of the "labile" site (later equated to $\mathrm{Ni}_{\mathrm{p}}$ ) with phenanthroline, the rising-edge feature (attributable to the "nonlabile" site and hence equated to $\mathrm{Ni}_{\mathrm{d}}$ ) becomes less intense, ${ }^{60}$ which is contrary to the finding that the $\mathrm{Ni}_{\mathrm{d}}$ site is square-planar in nature. There are also significant limitations to the EXAFS studies of the ACS active site published after the discovery that the active site has two Ni centers. For example, Svetlitchnyi et al. performed EXAFS analysis of a sample of only as-isolated ACS; however, the data are fairly marginal (reliable only to $k \sim 11 \AA^{-1}$ ). ${ }^{7}$ Gu et al. performed a more comprehensive EXAFS study; ${ }^{59}$ however, their XANES data for the as-isolated protein resemble those of the phenathrolinetreated protein, ${ }^{60}$ indicating significant removal of the $\mathrm{Ni}_{\mathrm{p}}$ site. Because the $\mathrm{Ni}$ K-edge EXAFS figure in the paper is incorrect (the Fe K-edge EXAFS data are shown in the Ni Kedge EXAFS figure), a direct comparison of the two postcrystal structure EXAFS data is not possible. More importantly, the study does not show a significant change in the near-edge, pre-edge, or Fourier transforms upon $\mathrm{CO}$ treatment, indicating that an insignificant amount of the $\mathrm{Ni}-\mathrm{CO}$ species was present in the sample. A more recent conference proceeding ${ }^{69}$ shows low-resolution Ni K-edge EXAFS data $\left(k \sim 12 \AA^{-1}\right)$ on partially loaded as-isolated and reduced ACS, which are quantitatively different from those of Cramer et al. ${ }^{59}$ To complicate the analysis further, an EXAFS study of ACS containing $\mathrm{Cu}$ at the proximal center (i.e., $\mathrm{Cu}_{\mathrm{p}} \mathrm{Ni}_{\mathrm{d}}$ ) shows a dramatically short $\mathrm{Cu}-\mathrm{Ni}$ distance $(2.67 \AA$ ) compared to the longer Ni-Ni distance observed in other studies $(\sim 2.9 \AA) .{ }^{37}$ These earlier Ni K-edge and EXAFS investigations performed on ACS have all yielded incorrect and at best incomplete information about the active site of ACS. Despite this, all the EXAFS studies are qualitatively consistent showing both $\mathrm{Ni}-\mathrm{S}$ and $\mathrm{Ni}-\mathrm{N} / \mathrm{O}$ coordination and a longer distance $\mathrm{Ni}$-metal interaction (see Table S2), properties that are consistent with the significantly higher quality theoretically validated EXAFS data presented here. 


\section{DFT Structural Correlation of $A_{O X}, A_{R E D}$, and $A_{\text {NiFeC }}$}

Quantum chemical assessment ${ }^{70}$ of the geometries of $A_{O X}, A_{R E D}$, and $A_{\mathrm{NiFeC}}$ states was performed starting with the geometrical parameters obtained from the crystal structure of $\mathrm{A}_{\mathrm{OX}}$ (PDB entry 1RU3) (details of the various geometries and A cluster states are given in the Supporting Information). ${ }^{7}$ For $\mathrm{A}_{\mathrm{NiFeC}}$, the $\mathrm{CO}$ was initially positioned near the $\mathrm{Ni}_{\mathrm{p}}$ site and assumed not to bind to the $\mathrm{Fe}-\mathrm{S}$ cluster or the $\mathrm{Ni}_{\mathrm{d}}$ site, consistent with the XAS data presented in the previous sections. For $\mathrm{A}_{\mathrm{OX}}$, optimizations without a fourth ligand led to unlikely perturbation of the $\mathrm{Fe}-\mathrm{S}$ cluster and $\mathrm{Ni}$-sulfide ligation. The four-coordinate structure was optimized to a square-planar geometry, irrespective of starting geometry (Figure 6). Although it is likely that the four-coordinate $\mathrm{Ni}_{\mathrm{p}}$ in $\mathrm{A}_{\mathrm{OX}}$ would lose the water ligand upon reduction, DFT optimizations on $A_{R E D}$ with either a four- or three-coordinate site invariably led to Ni-sulfide ligation as observed for the three-coordinate $\mathrm{A}_{\mathrm{OX}}$. This is consistent with previous reports, in which a geometric constraint on the Ni-sulfide distance had to be imposed to theoretically evaluate the $A_{R E D}$ state. ${ }^{54}$ Because of the similarity of the $\mathrm{A}_{\mathrm{OX}}$ and $\mathrm{A}_{\mathrm{RED}}$ spectra, which indicate similar geometric and electronic structures for these two states, we compared geometry-optimized structures for $\mathrm{A}_{\mathrm{OX}}$ and $\mathrm{A}_{\mathrm{NiFeC}}$.

Geometry optimization on $\mathrm{A}_{\mathrm{NiFeC}}$ converged with $\mathrm{CO}$ bound at the $\mathrm{Ni}_{\mathrm{p}}$ site in a tetrahedral geometry. This is consistent with the Ni K-edge rising-edge data, which showed that although the $\mathrm{Ni}_{\mathrm{p}}$ site in $\mathrm{A}_{\mathrm{OX}}$ (and $\mathrm{A}_{\mathrm{RED}}$ ) is consistent with a square-planar structure, the $\mathrm{Ni}_{\mathrm{p}}$ site in $\mathrm{A}_{\mathrm{NiFeC}}$ is not. The calculated $\mathrm{Ni}-\mathrm{C}$ distance of $1.75 \AA$ is in good agreement with the EXAFS distance of $1.77 \AA$. The Ni-S distances for both the $\mathrm{Ni}_{\mathrm{d}}$ and $\mathrm{Ni}_{\mathrm{p}}$ sites increase in $\mathrm{A}_{\mathrm{NiFeC}}$ (Figure 6). The largest perturbation is in the $\mathrm{Ni}_{\mathrm{p}}-\mathrm{S}$ distance of the bridged $\mathrm{Ni}_{\mathrm{p}}-\mathrm{S}-\mathrm{Fe}$ (from 2.18 to $2.36 \AA$ ), in good agreement with the EXAFS data, which show elongation of the Ni-S distance from 2.18 to $2.22 \AA$ and splitting of the Ni-S contributions to include 0.5 $\mathrm{Ni}-\mathrm{S}$ group at $2.33 \AA$. The comparison of the DFT structure with the EXAFS data confirms that the elongated $\mathrm{Ni}-\mathrm{S}$ (obtained from the EXAFS data) is the $\mathrm{Ni}_{\mathrm{p}}-\mathrm{S}$ (Cys) of the bridging $\mathrm{Ni}_{\mathrm{p}}-\mathrm{S}-\mathrm{Fe}$ in ACS. Reduction followed by $\mathrm{CO}$ binding $\left(\mathrm{A}_{\mathrm{OX}}\right.$ to $\left.\mathrm{A}_{\mathrm{NiFeC}}\right)$ leads to elongation of the Ni-Fe bond by $1.1 \AA$, while the Ni-Ni bond is shortened by $0.38 \AA$, consistent with the EXAFS results, which show a shortening of the Ni-metal bond. In summary, the experimental and theoretical data reveal a tetrahedral $\mathrm{Ni}_{\mathrm{p}}$ site with a short $\mathrm{Ni}_{\mathrm{p}}-\mathrm{C}$ bond, longer $\mathrm{Ni}-\mathrm{S}$ distances, especially the $\mathrm{Ni}_{\mathrm{p}}-\mathrm{S}(\mathrm{Cys})$ bond, and a shorter distance $\mathrm{Ni}_{\mathrm{p}}-\mathrm{Ni}_{\mathrm{d}}$ interaction.

The structural models developed here were used to evaluate the Ni K-pre-edge data presented in Figure 5A, which show two pre-edge features for $\mathrm{A}_{\mathrm{NiFeC}}$ occurring at energies slightly lower than that of the single pre-edge feature in $\mathrm{A}_{\mathrm{OX}}$. Ni 1s $\rightarrow 3 \mathrm{~d}$ TD-DFT calculations (including both $\mathrm{Ni}_{\mathrm{p}}$ and $\mathrm{Ni}_{\mathrm{d}}$ sites) ${ }^{71}$ were performed on $\mathrm{A}_{\mathrm{OX}}$ and $\mathrm{A}_{\mathrm{NiFeC}}$ using the geometry-optimized structures (Figure 7). The calculations show a single peak in $\mathrm{A}_{\mathrm{OX}}$ at $8328.7 \mathrm{eV}$ and two peaks separated by $\sim 0.8 \mathrm{eV}$ (8328.2 and $8329.0 \mathrm{eV}$ ) for $\mathrm{A}_{\mathrm{NiFeC}}$, which is in excellent agreement with the experimental pre-edge energy separation. Individual $1 \mathrm{~s} \rightarrow$ $3 \mathrm{~d}$ calculations from the $\mathrm{Ni}_{\mathrm{p}}$ and $\mathrm{Ni}_{\mathrm{d}}$ sites show that while both contribute at the same energy for $\mathrm{A}_{\mathrm{OX}}$, they contribute dominantly to the 8328.2 and $8329.0 \mathrm{eV}$ features, respectively. The lower pre-edge energy position for $\mathrm{Ni}_{\mathrm{p}}$ in $\mathrm{A}_{\mathrm{NiFeC}}$ indicates a decrease in its ligand-field strength relative to that of $\mathrm{A}_{\mathrm{OX}}$, which is consistent with a partially reduced $\mathrm{Ni}_{\mathrm{p}}$ 
that has significantly elongated Ni-S distances. Both of these factors effectively offset the increase in ligand field due to the formation of the $\mathrm{Ni}-\mathrm{CO}$ bond and lower the pre-edge energy position. This large structural and electronic perturbation is consistent with the idea that the $\mathrm{Ni}_{\mathrm{p}}$ site is highly labile and flexible and can assume drastically different electronic configurations during catalysis.

\section{IMPLICATIONS}

Our results convincingly demonstrate that biological acetate synthesis occurs through formation of an organometallic $\mathrm{Ni}-\mathrm{CO}$ intermediate, thus validating a central tenet of the unique organometallic pathway used by a wide class of anaerobic bacteria in energy metabolism and carbon dioxide fixation. Acetyl-CoA synthase (ACS), the key enzyme in anaerobic $\mathrm{CO}$ and $\mathrm{CO}_{2}$ fixation, catalyzes the production of acetyl-CoA from $\mathrm{CO}$, a methyl group and CoA as part of the Wood-Ljungdahl pathway. ${ }^{4}$ Various lines of evidence support the concept that this pathway involves an organometallic reaction sequence in which the $\mathrm{CO}$, methyl, and CoA components of acetyl-CoA bind sequentially to a metal center in the A cluster of ACS (Figure 2). Because of the novelty of Ni in the enzyme and the lack of any structural information about the complexity of this cluster (later shown to be a dinickel unit bridged to a [4Fe-4S] cluster), it was proposed three decades ago that acetyl-CoA assembly took place at $\mathrm{Ni} ;{ }^{1}$ however, direct structural evidence of a nickel-carbon bond or, in fact, any type of metal-carbon bond on ACS has been lacking. The Ni K-edge XAS results provide this unambiguous structural evidence demonstrating that the carbon of $\mathrm{CO}$ binds to $\mathrm{Ni}_{\mathrm{p}}$ within the A cluster of ACS.

This $\mathrm{Ni}_{\mathrm{p}}(\mathrm{I})-\mathrm{CO}\left(\mathrm{A}_{\mathrm{NiFeC}}\right)$ species is shown as intermediate $\mathbf{3}$ in Figure 2. It is formed from intermediate species $\mathbf{1}\left(\mathrm{A}_{\mathrm{OX}}\right)$ through another intermediate $\mathbf{2}$, described here as $\mathrm{A}_{\text {red }}$ *, a highly labile paramagnetic $\mathrm{Ni}(\mathrm{I})$ state that has so far been observed only by photolysis of the $\mathrm{Ni}_{\mathrm{p}}(\mathrm{I})-\mathrm{CO}$ state. 35 The EPR spectrum of $\mathrm{A}_{\text {red }} *$ is significantly different from that of the $\mathrm{A}_{\mathrm{NiFeC}}$ species in that it exhibits $g$ values $(2.56,2.10$, and 2.01) similar to those of $\mathrm{Ni}(\mathrm{I})$ model compounds, ${ }^{72}$ suggestive of a $\mathrm{Ni}(\mathrm{I})$ state with little electron delocalization into the other subcomponents of the A cluster. The data presented here support previous results that indicate that $\mathrm{Ni}_{\mathrm{p}}$ (II) is not reduced by DTT, dithionite, or Ti(III) citrate alone; however, in the presence of $\mathrm{CO}$, the reduction of $\mathrm{A}_{\mathrm{OX}}$ is coupled to formation of $\mathrm{A}_{\mathrm{NiFeC}}$, described formally as a $\mathrm{Ni}(\mathrm{I})-\mathrm{CO}$ species. A combination of EXAFS and DFT results shows that when $\mathrm{CO}$ binds to ACS, $\mathrm{Ni}_{\mathrm{p}}$ converts from a square-planar $\mathrm{NiS}_{3} \mathrm{O}$ to tetrahedral $\mathrm{NiS}_{3} \mathrm{CO}$ site accompanied by a $0.16 \AA$ lengthening of the $\mathrm{Fe}-\mathrm{S}$ bond for the bridging $\mathrm{Ni}_{\mathrm{p}}-\mathrm{S}(\mathrm{Cys})-\mathrm{Fe}$ bond and $0.04 \AA$ elongation of the $\mathrm{Ni}_{\mathrm{p}}-\mathrm{S}(\mathrm{Cys})$ bridged to $\mathrm{Ni}_{\mathrm{d}}$. $\mathrm{Ni}_{\mathrm{d}}$ retains a $\mathrm{N}_{2} \mathrm{~S}_{2}$ squareplanar geometry but experiences a $0.04 \AA$ lengthening of the $\mathrm{Ni}_{\mathrm{d}}-\mathrm{S}$ bond upon reduction and $\mathrm{CO}$ binding to $\mathrm{Ni}_{\mathrm{p}}$. This, along with the short $\mathrm{Ni}-\mathrm{Ni}$ distance predicted by DFT (Figure 6), suggests a subtle structural/electronic role of $\mathrm{Ni}_{\mathrm{d}}$ in forming $\mathrm{A}_{\mathrm{NiFeC}}$. One might ask if a simple $\mathrm{Ni}-\mathrm{CO}$ model complex or peptide may have structural, spectroscopic, and/or catalytic properties similar to those of the A cluster containing five other thiol-associated metal ions embedded within a large protein.

While $\mathrm{A}_{\mathrm{NiFeC}}$ and $\mathrm{A}_{\text {red }}$ * are one-electron reduced species relative to $\mathrm{A}_{\mathrm{OX}}$, our results indicate that the species traditionally called $\mathrm{A}_{\mathrm{RED}}$ actually is equivalent to $\mathrm{A}_{\mathrm{OX}}$. This is in 
contrast to "free" $[4 \mathrm{Fe}-4 \mathrm{~S}]^{2+}$ clusters such as that present in the Fe protein in nitrogenase, ${ }^{55,56}$ which undergo reduction in the presence of dithionite accompanied by significant changes in the UV-visible spectra and in the Fe K-edge XAS and EXAFS. The only time that the $[4 \mathrm{Fe}-4 \mathrm{~S}]$ cluster undergoes reduction is in the Ni-depleted protein, so we propose that this might be the species more properly designated as $A_{R E D}$. Thus, $A_{R E D}$, defined as the state of the A cluster that undergoes reduction in the absence of $\mathrm{CO}$ to generate a reduced $[4 \mathrm{Fe}-4 \mathrm{~S}]$ cluster, is not part of the ACS catalytic cycle.

Upon reaction of $\mathrm{A}_{\mathrm{NiFeC}}$ with the methylated CFeSP, a putative methyl-Ni(III) species, 4 , is formed, which is expected to be a highly oxidizing and unstable intermediate that would undergo immediate one-electron reduction to generate $\mathbf{5}$, requiring a net one-electron uptake and positing a net input of two electrons between $\mathbf{1}$ and $\mathbf{5}$. The second electron is obtained from internal electron transfer, but the actual site for docking of that one electron has not been identified. ${ }^{15}$ Nucleophilic attack by CoA would then lead to reductive elimination of the acetyl group as acetyl-CoA to regenerate 2 . Acetyl-CoA formation from a metalcarbonyl species is analogous to some well-known industrial processes involving carbonylation chemistry, including the Monsanto process, hydroformylation, and the Reppe process. ${ }^{73}$ The intermediate steps in the Monsanto process for formation of acetic acid from methanol and CO are nearly identical to those in the catalytic mechanism of ACS in that both use organometallic mechanisms that feature low-valent metal centers [e.g., $\mathrm{Rh}(\mathrm{I}) \mathrm{vs}$ $\mathrm{Ni}(\mathrm{I})]$ to react with $\mathrm{CO}$ to form a metal-carbonyl bond (M-CO) or with a methyl donor to generate a methyl-metal bond $\left(\mathrm{M}-\mathrm{CH}_{3}\right)$ that undergoes carbonyl insertion (methyl migration) and reaction with a nucleophile to generate an activated form of acetate (acetyl iodide instead of acetyl-CoA). Thus, it is interesting to consider how the ACS active site is poised to catalyze $\mathrm{C}-\mathrm{C}$ and $\mathrm{C}-\mathrm{S}$ bond formation, while $\mathrm{CODH}$, which also contains a $\mathrm{Ni}$ ion bridged to a $[4 \mathrm{Fe}-4 \mathrm{~S}]$ cluster, proficiently catalyzes $\mathrm{CO}$ oxidation and/or $\mathrm{CO}_{2}$ reduction.

\title{
Supplementary Material
}

Refer to Web version on PubMed Central for supplementary material.

\section{Acknowledgments}

Portions of this research were performed at the Stanford Synchrotron Radiation Lightsource, a Directorate of SLAC National Accelerator Laboratory and an Office of Science User Facility operated for the U.S. Department of Energy (DOE) Office of Science by Stanford University. The SSRL Structural Molecular Biology Program is supported by the DOE Office of Biological and Environmental Research and by the National Institutes of Health, National Institute of General Medical Sciences (including Grant P41GM103393).

Funding

This work was supported by Grant R37-GM39451 (S.W.R.).

\section{ABBREVIATIONS}

\author{
ACS acetyl-CoA synthase \\ ACDS acetyl-CoA decarbonylase/synthase \\ CODH CO dehydrogenase
}




$\begin{array}{ll}\text { CFeSP } & \text { corrinoid iron-sulfur protein } \\ \text { DFT } & \text { density functional theory } \\ \text { EPR } & \text { electron paramagnetic resonance } \\ \text { EXAFS } & \text { extended X-ray absorption fine structure } \\ \text { Ni }_{\mathbf{p}} & \text { Ni atom proximal to the } \mathrm{Fe}_{4} \mathrm{~S}_{4} \text { subcluster } \\ \mathbf{N i}_{\mathbf{d}} & \text { Ni atom distal to the } \mathrm{Fe}_{4} \mathrm{~S}_{4} \text { subcluster } \\ \text { TD } & \text { time-dependent } \\ \text { XAS } & \text { X-ray absorption spectroscopy } \\ \text { XANES } & \text { X-ray near-edge spectroscopy }\end{array}$

\section{References}

1. Ragsdale SW, Wood HG. Acetate biosynthesis by acetogenic bacteria: evidence that carbon monoxide dehydrogenase is the condensing enzyme that catalyzes the final steps of the synthesis. $\mathbf{J}$ Biol Chem. 1985; 260:3970-3977. [PubMed: 2984190]

2. Kumar M, Lu WP, Liu L, Ragsdale SW. Kinetic evidence that CO dehydrogenase catalyzes the oxidation of CO and the synthesis of acetyl-CoA at separate metal centers. J Am Chem Soc. 1993; 115:11646-11647.

3. Xia J, Sinclair JF, Baldwin TO, Lindahl PA. Carbon monoxide dehydrogenase from Clostridium thermoaceticum: quaternary structure, stoichiometry of its SDS-induced dissociation, and characterization of the faster-migrating form. Biochemistry. 1996; 35:1965-1971. [PubMed: 8639680]

4. Can M, Armstrong FA, Ragsdale SW. Structure, Function, and Mechanism of the Nickel Metalloenzymes, CO Dehydrogenase, and Acetyl-CoA Synthase. Chem Rev. 2014; 114:4149-4174. [PubMed: 24521136]

5. Doukov TI, Iverson T, Seravalli J, Ragsdale SW, Drennan CL. A Ni-Fe-Cu center in a bifunctional carbon monoxide dehydrogenase/acetyl-CoA synthase. Science. 2002; 298:567-572. [PubMed: 12386327]

6. Darnault C, Volbeda A, Kim EJ, Legrand P, Vernede X, Lindahl PA, Fontecilla-Camps JC. Ni-Zn$\left[\mathrm{Fe}_{4}-\mathrm{S}_{4}\right]$ and $\mathrm{Ni}-\mathrm{Ni}-\left[\mathrm{Fe}_{4}-\mathrm{S}_{4}\right]$ clusters in closed and open alpha subunits of acetyl-CoA synthase/ carbon monoxide dehydrogenase. Nat Struct Biol. 2003; 10:271-279. [PubMed: 12627225]

7. Svetlitchnyi V, Dobbek H, Meyer-Klaucke W, Meins T, Thiele B, Romer P, Huber R, Meyer O. A functional $\mathrm{Ni}-\mathrm{Ni}$-[4Fe-4S] cluster in the monomeric acetyl-CoA synthase from Carboxydothermus hydrogenoformans. Proc Natl Acad Sci U S A. 2004; 101:446-451. [PubMed: 14699043]

8. Drennan CL, Doukov TI, Ragsdale SW. The Metalloclusters of Carbon Monoxide Dehydrogenase/ Acetyl-CoA Synthase: A Story in Pictures. JBIC, J Biol Inorg Chem. 2004; 9:511-515. [PubMed: 15221484]

9. Seravalli J, Ragsdale SW. Pulse-chase studies of the synthesis of acetyl-CoA by carbon monoxide dehydrogenase/acetyl-CoA synthase - Evidence for a random mechanism of methyl and carbonyl addition. J Biol Chem. 2008; 283:8384-8394. [PubMed: 18203715]

10. Ragsdale SW. Metals and their scaffolds to promote difficult enzymatic reactions. Chem Rev. 2006; 106:3317-3337. [PubMed: 16895330]

11. Lindahl PA. Acetyl-coenzyme A synthase: the case for a $\mathrm{Ni}_{\mathrm{p}}(0)$-based mechanism of catalysis. JBIC, J Biol Inorg Chem. 2004; 9:516-524. [PubMed: 15221478]

12. Seravalli J, Kumar M, Ragsdale SW. Rapid kinetic studies of acetyl-CoA synthesis: evidence supporting the catalytic intermediacy of a paramagnetic NiFeC species in the autotrophic WoodLjungdahl pathway. Biochemistry. 2002; 41:1807-1819. [PubMed: 11827525] 
13. Gorst CM, Ragsdale SW. Characterization of the NiFeCO Complex of Carbon-Monoxide Dehydrogenase as a Catalytically Competent Intermediate in the Pathway of Acetyl-Coenzyme-a Synthesis. J Biol Chem. 1991; 266:20687-20693. [PubMed: 1657934]

14. George SJ, Seravalli J, Ragsdale SW. EPR and infrared spectroscopic evidence that a kinetically competent paramagnetic intermediate is formed when acetyl-coenzyme A synthase reacts with CO. J Am Chem Soc. 2005; 127:13500-13501. [PubMed: 16190705]

15. Bender G, Ragsdale SW. Evidence That Ferredoxin Interfaces with an Internal Redox Shuttle in Acetyl-CoA Synthase during Reductive Activation and Catalysis. Biochemistry. 2011; 50:276286. [PubMed: 21141812]

16. Bender G, Stich TA, Yan L, Britt RD, Cramer SP, Ragsdale SW. Probing the catalytic mechanism of acetyl-CoA synthase by infrared and EPR characterization of the photolyzed Ni(I)-CO intermediate. Biochemistry. 2010; 49:7516-7523. [PubMed: 20669901]

17. Ragsdale SW. Nickel and the Carbon Cycle. J Inorg Biochem. 2007; 101:1657-1666. [PubMed: 17716738]

18. Bramlett MR, Stubna A, Tan X, Surovtsev IV, Munck E, Lindahl PA. Mossbauer and EPR study of recombinant acetyl-CoA synthase from Moorella thermoacetica. Biochemistry. 2006; 45:86748685. [PubMed: 16834342]

19. Gencic S, Grahame DA. Two Separate One-Electron Steps in the Reductive Activation of the A Cluster in Subunit beta of the ACDS Complex in Methanosarcina thermophila. Biochemistry. 2008; 47:5544-5555. [PubMed: 18442256]

20. Tan X, Martinho M, Stubna A, Lindahl PA, Munck E. Mossbauer Evidence for an ExchangeCoupled $\left\{\left[\mathrm{Fe}_{4} \mathrm{~S}_{4}\right]^{1+} \mathrm{Ni}_{\mathrm{p}}{ }^{1+}\right\}$ A-Cluster in Isolated alpha Subunits of Acetyl-Coenzyme A Synthase/Carbon Monoxide Dehydrogenase. J Am Chem Soc. 2008; 130:6712-6713. [PubMed: 18459773]

21. Seravalli J, Ragsdale SW. Pulse-Chase Studies of the Synthesis of Acetyl-CoA by Carbon Monoxide Dehydrogenase/Acetyl-CoA Synthase: Evidence for a Random Mechanism of Methyl and Carbonyl Addition. J Biol Chem. 2008; 283:8384-8394. [PubMed: 18203715]

22. Lu WP, Harder SR, Ragsdale SW. Controlled Potential Enzymology of Methyl Transfer-Reactions Involved in Acetyl-CoA Synthesis by Co Dehydrogenase and the Corrinoid Iron-Sulfur Protein from Clostridium thermoaceticum. J Biol Chem. 1990; 265:3124-3133. [PubMed: 2303444]

23. Tan XS, Sewell C, Lindahl PA. Stopped-Flow Kinetics of Methyl Group Transfer between the Corrinoid-Iron-Sulfur Protein and Acetyl-Coenzyme A Synthase from Clostridium thermoaceticum. J Am Chem Soc. 2002; 124:6277-6284. [PubMed: 12033855]

24. Ragsdale SW, Ljungdahl LG, DerVartanian DV. EPR evidence for nickel substrate interaction in carbon monoxide dehydrogenase from Clostridium thermoaceticum. Biochem Biophys Res Commun. 1982; 108:658-663. [PubMed: 6293499]

25. Ragsdale SW, Ljungdahl LG, DerVartanian DV. ${ }^{13} \mathrm{C}$ and ${ }^{61} \mathrm{Ni}$ isotope substitution confirm the presence of a nickel(III)-carbon species in acetogenic $\mathrm{CO}$ dehydrogenases. Biochem Biophys Res Commun. 1983; 115:658-665. [PubMed: 6312988]

26. Ragsdale SW, Wood HG, Antholine WE. Evidence that an iron-nickel-carbon complex is formed by reaction of $\mathrm{CO}$ with the $\mathrm{CO}$ dehydrogenase from Clostridium thermoaceticum. Proc Natl Acad Sci U S A. 1985; 82:6811-6814. [PubMed: 2995986]

27. Ragsdale SW, Pierce E. Acetogenesis and the Wood-Ljungdahl Pathway of $\mathrm{CO}_{2}$ Fixation. Biochim Biophys Acta, Proteins Proteomics. 2008; 1784:1873-1898.

28. Schiel-Bengelsdorf B, Durre P. Pathway engineering and synthetic biology using acetogens. FEBS Lett. 2012; 586:2191-2198. [PubMed: 22710156]

29. Ferry JG. Enzymology of one-carbon metabolism in methanogenic pathways. FEMS Microbiol Rev. 1999; 23:13-38. [PubMed: 10077852]

30. Martin W, Russell MJ. On the origin of biochemistry at an alkaline hydrothermal vent. Philos Trans R Soc, B. 2007; 362:1887-1925.

31. Fan C, Gorst CM, Ragsdale SW, Hoffman BM. Characterization of the Ni-Fe-C complex formed by reaction of carbon monoxide with the carbon monoxide dehydrogenase from Clostridium thermoaceticum by Q-band ENDOR. Biochemistry. 1991; 30:431-435. [PubMed: 1846295] 
32. Lindahl PA, Münck E, Ragsdale SW. CO dehydrogenase from Clostridium thermoaceticum: EPR and electrochemical studies in $\mathrm{CO}_{2}$ and argon atmospheres. J Biol Chem. 1990; 265:3873-3879. [PubMed: 2154491]

33. Lindahl PA, Ragsdale SW, Münck E. Mössbauer studies of CO dehydrogenase from Clostridium thermoaceticum. J Biol Chem. 1990; 265:3880-3888. [PubMed: 2303484]

34. Doukov TI, Blasiak LC, Seravalli J, Ragsdale SW, Drennan CL. Xenon in and the end of the tunnel of bifunctional Carbon Monoxide Dehydrogenase/Acetyl-CoA Synthase. Biochemistry. 2008; 47:3474-3483. [PubMed: 18293927]

35. Bender G, Stich TA, Yan L, Britt RD, Cramer SP, Ragsdale SW. Infrared and EPR spectroscopic characterization of a $\mathrm{Ni}(\mathrm{I})$ species formed by photolysis of a catalytically competent $\mathrm{Ni}(\mathrm{I})-\mathrm{CO}$ intermediate in the acetyl-CoA synthase reaction. Biochemistry. 2010; 49:7516-7523. [PubMed: 20669901]

36. Shin WS, Lindahl PA. Low-Spin Quantitation of Nifec Epr Signal from Carbon-Monoxide Dehydrogenase Is Not Due to Damage Incurred during Protein-Purification. Biochim Biophys Acta, Protein Struct Mol Enzymol. 1993; 1161:317-322.

37. Seravalli J, Xiao Y, Gu W, Cramer SP, Antholine WE, Krymov V, Gerfen GJ, Ragsdale SW. Evidence That Ni-Ni Acetyl-CoA Synthase Is Active And That The Cu-Ni Enzyme Is Not. Biochemistry. 2004; 43:3944-3955. [PubMed: 15049702]

38. Schenker RP, Brunold TC. Computational studies on the A cluster of acetyl-coenzyme A synthase: geometric and electronic properties of the $\mathrm{NiFeC}$ species and mechanistic implications. $\mathrm{J} \mathrm{Am}$ Chem Soc. 2003; 125:13962-13963. [PubMed: 14611224]

39. Harrop TC, Olmstead MM, Mascharak PK. Synthetic analogues of the active site of the A-cluster of acetyl coenzyme A synthase/CO dehydrogenase: syntheses, structures, and reactions with CO. Inorg Chem. 2006; 45:3424-3436. [PubMed: 16602803]

40. Mathrubootham V, Thomas J, Staples R, McCraken J, Shearer J, Hegg EL. Bisamidate and Mixed Amine/Amidate $\mathrm{NiNi}_{2} \mathrm{~S}_{2}$ Complexes as Models for Nickel-Containing Acetyl Coenzyme A Synthase and Superoxide Dismutase: An Experimental and Computational Study. Inorg Chem. 2010; 49:5393-5406. [PubMed: 20507077]

41. Matsumoto T, Ito M, Kotera M, Tatsumi K. A dinuclear nickel complex modeling of the $\mathrm{Ni}_{\mathrm{d}}(\mathrm{II})$ $\mathrm{Ni}_{\mathrm{p}}$ (I) state of the active site of acetyl CoA synthase. Dalton transactions. 2010; 39:2995-2997. [PubMed: 20221531]

42. Raybuck SA, Bastian NR, Orme-Johnson WH, Walsh CT. Kinetic characterization of the carbon monoxide-acetyl-CoA (carbonyl group) exchange activity of the acetyl-CoA synthesizing CO dehydrogenase from Clostridium thermoaceticum. Biochemistry. 1988; 27:7698-7702. [PubMed: 2905170]

43. Li CW, Yu JH, Liang YM, Chou YH, Park HJ, Choo KH, Chen SS. Ni removal from aqueous solutions by chemical reduction: Impact of $\mathrm{pH}$ and pe in the presence of citrate. J Hazard Mater. 2016; 320:521-528. [PubMed: 27597152]

44. Tenderholt, A., Hedman, B., Hodgson, KO. PySpline: A Modern, Cross-Platform Program for the Processing of Raw Averaged XAS Edge and EXAFS Data. In: Hedman, B., Pianetta, P., editors. X-ray Absorption Fine Structure: XAFS13. American Institute of Physics, Stanford University; 2007. p. 105-107.

45. Rehr JJ, Mustre de Leon J, Zabinsky SI, Albers RC. Theoretical X-Ray Absorption Fine-Structure Standards. J Am Chem Soc. 1991; 113:5135-5140.

46. Zabinsky SI, Rehr JJ, Ankudinov A, Albers RC, Eller MJ. Multiple-Scattering Calculations of XRay-Absorption Spectra. Phys Rev B: Condens Matter Mater Phys. 1995; 52:2995-3009.

47. George, GN. EXAFSPAK and EDG-FIT. Stanford Synchrotron Radiation Laboratory, Stanford Linear Accelerator Center; Stanford, CA: 2000.

48. Hamilton W. Significance tests on the crystallographic R factor. Acta Crystallogr. 1965; 18:502510.

49. Neese, F. ORCA: An Ab initio, DFT and Semiempirical Electronic Structure Package, version 2.6.35. University of Bonn; Bonn, Germany: 2008.

50. Neese F, Olbrich G. ORCA publication. Chem Phys Lett. 2002; 362:170-178. 
51. Neese, F. ORCA: An ab initio, DFT and semiempirical SCF-MO package, version 3.0.3. University of Bonn; Bonn, Germany: 2016.

52. Weigend F, Ahlrichs R. Balanced basis sets of split valence, triple zeta valence and quadruple zeta valence quality for H to Rn: Design and assessment of accuracy. Phys Chem Chem Phys. 2005; 7:3297-3305. [PubMed: 16240044]

53. Sinnecker S, Rajendran A, Klamt A, Diedenhofen M, Neese F. Calculation of solvent shifts on electronic g-tensors with the conductor-like screening model (COSMO) and its self-consistent generalization to real solvents (direct COSMO-RS). J Phys Chem A. 2006; 110:2235-2245. [PubMed: 16466261]

54. Chmielowska A, Lodowski P, Jaworska M. Redox Potentials and Protonation of the A-Cluster from Acetyl-CoA Synthase. A Density Functional Theory Study. J Phys Chem A. 2013; 117:1248412496. [PubMed: 24088138]

55. Musgrave KB, Angove HC, Burgess BK, Hedman B, Hodgson KO. All-Ferrous Titanium(III) Citrate Reduced Fe Protein of Nitrogenase: An XAS Study of Electronic and Metrical Structure. J Am Chem Soc. 1998; 120:5325-5326.

56. Mitra D, George SJ, Guo Y, Kamali S, Keable S, Peters JW, Pelmenschikov V, Case DA, Cramer SP. Characterization of [4Fe-4S] Cluster Vibrations and Structure in Nitrogenase Fe Protein at Three Oxidation Levels via Combined NRVS, EXAFS, and DFT Analyses. J Am Chem Soc. 2013; 135:2530-2543. [PubMed: 23282058]

57. Sarangi R. X-ray absorption near-edge spectroscopy in bioinorganic chemistry: Application to MO systems. Coord Chem Rev. 2013; 257:459-472. [PubMed: 23525635]

58. DuBois JL, Mukherjee P, Stack TDP, Hedman B, Solomon EI, Hodgson KO. A Systematic K-edge X-ray Absorption Spectroscopic Study of Cu(III) Sites. J Am Chem Soc. 2000; 122:5775-5787.

59. Gu W, Gencic S, Cramer SP, Grahame DA. The A-cluster in subunit beta of the acetyl-CoA decarbonylase/synthase complex from Methanosarcina thermophila: Ni and Fe K-edge XANES and EXAFS analyses. J Am Chem Soc. 2003; 125:15343-15351. [PubMed: 14664578]

60. Russell WK, Stalhandske CMV, Xia JQ, Scott RA, Lindahl PA. Spectroscopic, redox, and structural characterization of the Ni-labile and nonlabile forms of the acetyl-CoA synthase active. Site of carbon monoxide dehydrogenase. J Am Chem Soc. 1998; 120:7502-7510.

61. Xia JQ, Dong J, Wang SK, Scott RA, Lindahl PA. EXAFS, EPR, and electronic absorption spectroscopic study of the alpha metallosubunit of CO dehydrogenase from Clostridium thermoaceticum. J Am Chem Soc. 1995; 117:7065-7070.

62. Mayhew SG. The redox potential of dithionite and $\mathrm{SO}_{2}{ }^{-}$from equilibrium reactions with flavodoxins, methyl viologen and hydrogen plus hydrogenase. Eur J Biochem. 1978; 85:535-547. [PubMed: 648533]

63. Westre TE, Kennepohl P, DeWitt JG, Hedman B, Hodgson KO, Solomon EI. A Multiplet Analysis of Fe K-Edge 1s $\rightarrow$ 3d Pre-Edge Features of Iron Complexes. J Am Chem Soc. 1997; 119:62976314.

64. Lindahl, PA., Graham, DE. Acetyl-Coenzyme A Synthases and Nickel Containing Carbon Monoxide Dehydrogenases. In: Sigel, A.Sigel, H., Sigel, RKO., editors. Nickel and its Surprising Impact in Nature. John Wiley and Sons; West Sussex, England: 2007. p. 357-416.

65. Lu WP, Ragsdale SW. Reductive activation of the coenzyme A/acetyl-CoA isotopic exchange reaction catalyzed by carbon monoxide dehydrogenase from Clostridium thermoaceticum and its inhibition by nitrous oxide and carbon monoxide. J Biol Chem. 1991; 266:3554-3564. [PubMed: 1995618]

66. Bhaskar B, DeMoll E, Grahame DA. Redox-dependent acetyl transfer partial reaction of the acetylCoA Decarbonylase/Synthase complex: kinetics and mechanism. Biochemistry. 1998; 37:1449114499. [PubMed: 9772177]

67. Colpas GJ, Maroney MJ, Bagyinka C, Kumar M, Willis WS, Suib SL, Mascharak PK, Baidya N. $\mathrm{X}$-ray spectroscopic studies of nickel complexes, with application to the structure of nickel sites in hydrogenases. Inorg Chem. 1991; 30:920-928.

68. Cramer SP, Eidsness MK, Pan WH, Morton TA, Ragsdale SW, DerVartanian DV, Ljungdahl LG, Scott RA. X-ray absorption spectroscopic evidence for a unique nickel site in Clostridium thermoaceticum carbon monoxide dehydrogenase. Inorg Chem. 1987; 26:2477-2479. 
69. Schrapers P, Mebs S, Ilina Y, Warner DS, Wörmann C, Schuth N, Kositzki R, Dau H, Limberg C, Dobbek H, Haumann M. The binuclear nickel center in the A-cluster of acetyl-CoA synthase (ACS) and two biomimetic dinickel complexes studied by X-ray absorption and emission spectroscopy. J Phys: Conf Ser. 2016; 712:012029.

70. Neese F. The ORCA program system. Wiley Interdisciplinary Reviews: Computational Molecular Science. 2012; 2:73-78.

71. DeBeer George S, Petrenko T, Neese F. Prediction of iron K-edge absorption spectra using timedependent density functional theory. J Phys Chem A. 2008; 112:12936-12943. [PubMed: 18698746]

72. Manesis AC, Shafaat HS. Electrochemical, Spectroscopic, and Density Functional Theory Characterization of Redox Activity in Nickel-Substituted Azurin: A Model for Acetyl-CoA Synthase. Inorg Chem. 2015; 54:7959-7967. [PubMed: 26234790]

73. Appel A, Bercaw J, Bocarsly A, Dobbek H, DuBois D, Dupuis M, Ferry J, Fujita E, Hille R, Kenis P, Kerfeld C, Morris R, Peden C, Portis A, Ragsdale S, Rauchfuss T, Reek J, Seefeldt L, Thauer R, Waldrop G. Frontiers, Opportunities, and Challenges in Biochemical and Chemical Catalysis of $\mathrm{CO}_{2}$ Fixation. Chem Rev. 2013; 113:6621-6658. [PubMed: 23767781] 

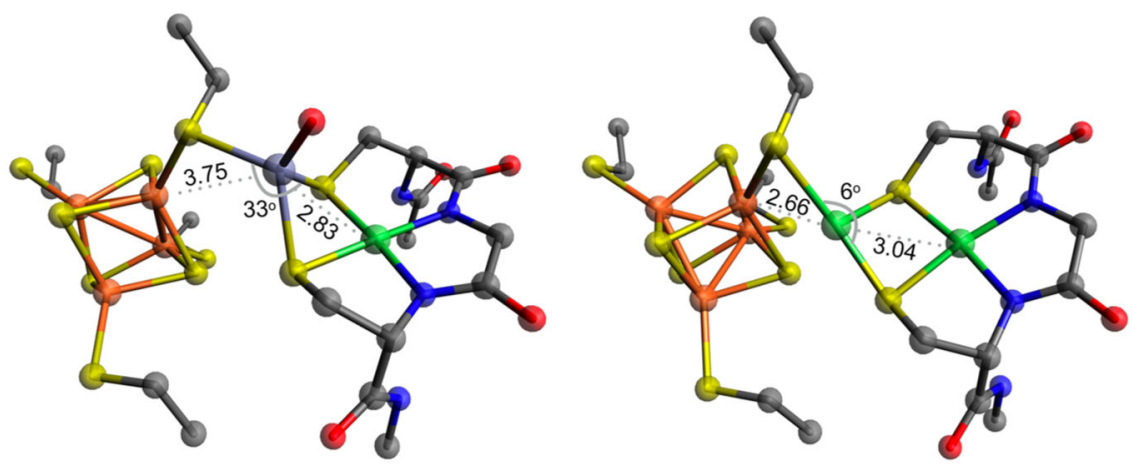

Figure 1.

ACS active site determined by crystallography (PDB entry 1OAO, Moorella thermoacetica). "Closed" conformation (the access path from the CODH Ni-Fe center to the ACS active site is closed) showing $\mathrm{Zn}$ occupancy at the tetrahedral $\mathrm{Ni}_{\mathrm{p}}$ site (left). "Open" conformation with $\mathrm{Ni}$ at the square-planar $\mathrm{Ni}_{\mathrm{p}}$ site (right). The $\mathrm{S}-\mathrm{S}-\mathrm{S}-\mathrm{Ni}$ dihedral angle demonstrates the change in geometry between the sites. A large difference in the Ni-metal distances is observed. 

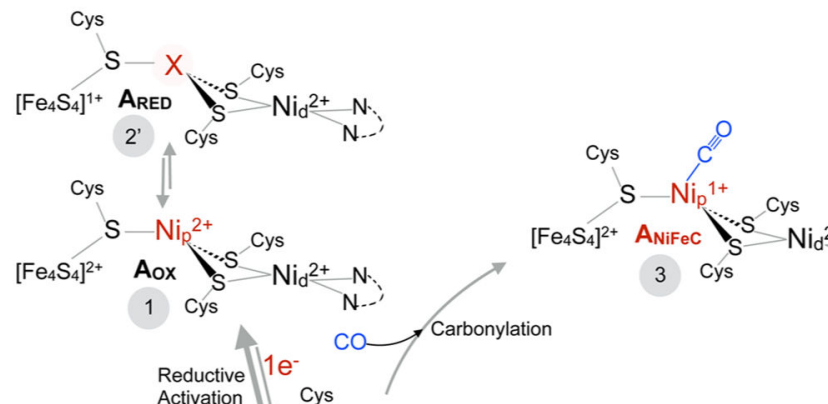

Activation 1 Cys

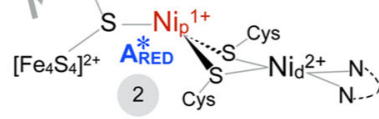

3 cys
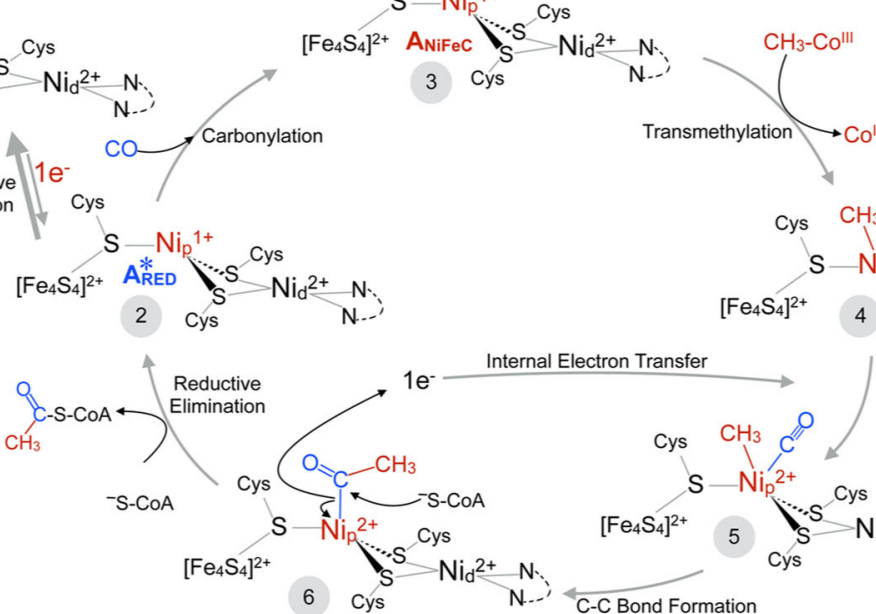

ernal Electron Transfer

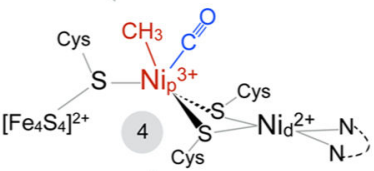

Random

Sequential

Mechanism

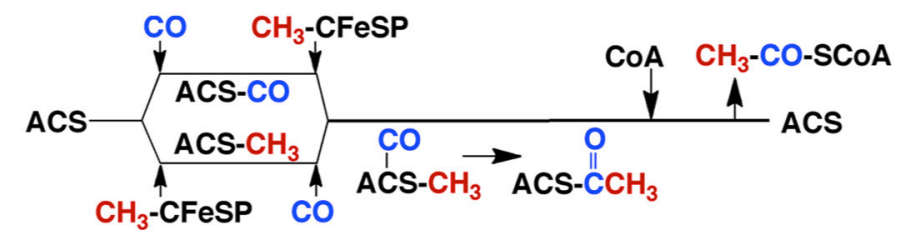

Figure 2.

Organometallic mechanism of acetyl-CoA synthesis. All steps are reversible. See the text for details. 


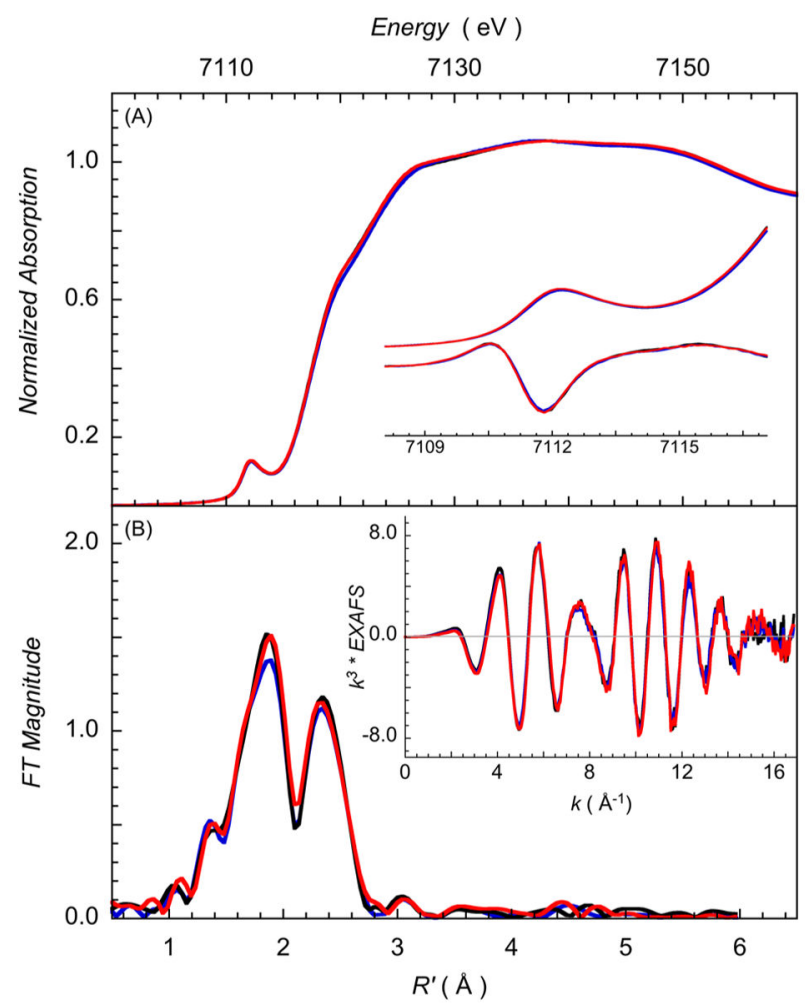

Figure 3.

Normalized Fe-edge XAS and EXAFS data for the three forms of ACS. (A) Normalized Fe K-edge XAS data for $\mathrm{A}_{\mathrm{OX}}$ (black), $\mathrm{A}_{\mathrm{RED}}$ (blue), and $\mathrm{A}_{\mathrm{NiFeC}}$ (red) states of ACS. The inset shows the expanded pre-edge region (inset, top) and the corresponding second derivatives (inset, bottom) for the pre-edge spectra. (B) Comparison of the non-phase-shift-corrected Fourier transforms and their corresponding EXAFS data (inset). 


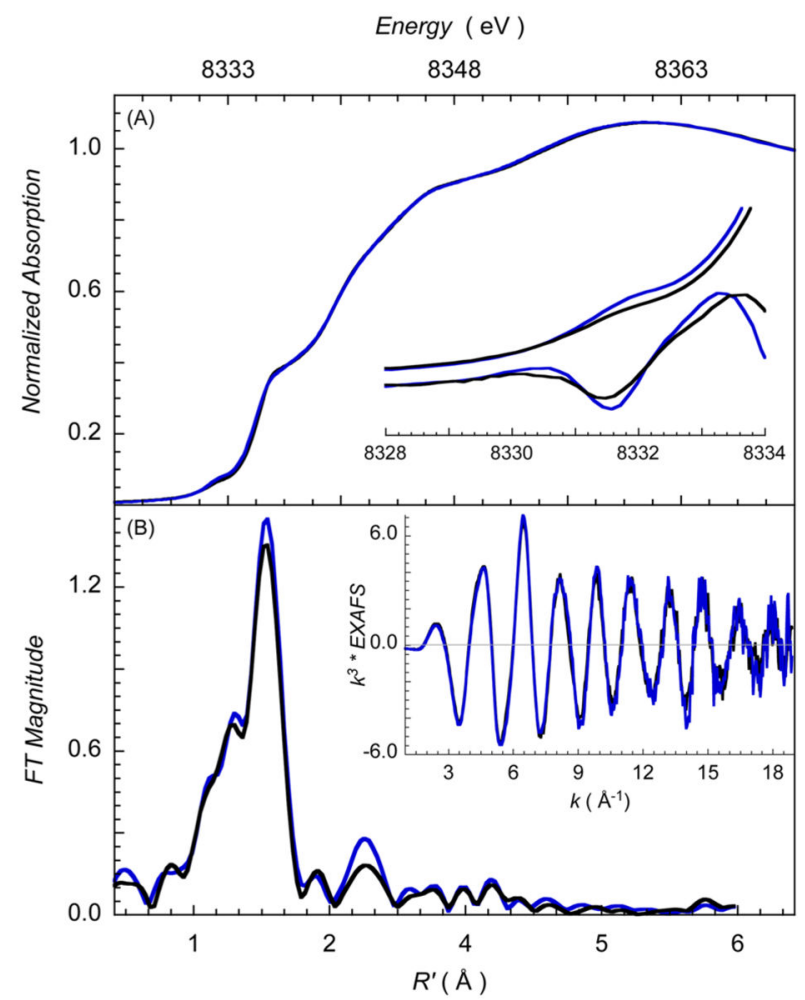

Figure 4.

XAS results for oxidized and dithionite-reduced states of ACS. (A) Normalized Ni K-edge XAS data for $A_{O X}$ (black) and $A_{R E D}$ (blue). The inset shows the expanded pre-edge region (inset, top) and the corresponding second derivatives (inset, bottom) for the pre-edge spectra. (B) Comparison of the non-phase-shift-corrected Fourier transforms and their corresponding EXAFS data (inset) for $A_{O X}$ (black) and $A_{R E D}$ (blue). 


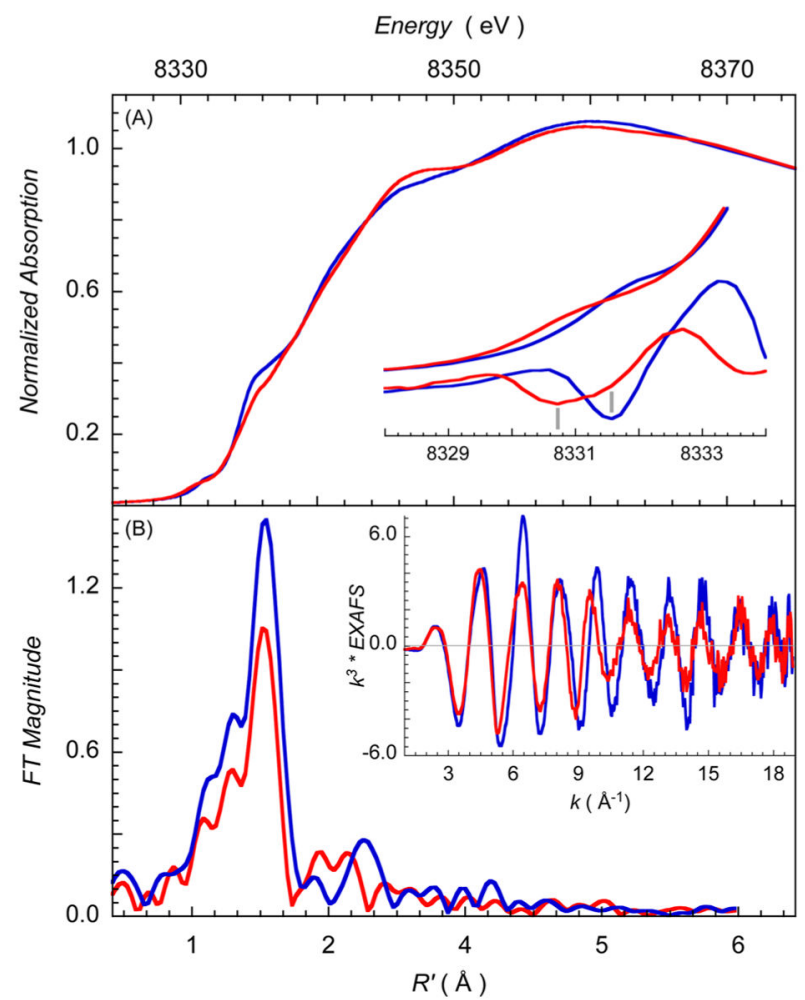

Figure 5.

Comparison of XAS results for dithionite-reduced and CO-bound forms of ACS. (A) Normalized Ni K-edge XAS data for $\mathrm{A}_{\mathrm{RED}}$ (blue) and $\mathrm{A}_{\mathrm{NiFeC}}$ (red). The inset shows the expanded pre-edge region (inset, top) and the corresponding second derivatives (inset, bottom) for the pre-edge spectra. The pre-edge features are marked with gray bars in the second derivative. (B) Comparison of the nonphase-shift-corrected Fourier transforms and their corresponding EXAFS data (inset) for $\mathrm{A}_{\mathrm{RED}}$ (blue) and $\mathrm{A}_{\mathrm{NiFeC}}$ (red). 

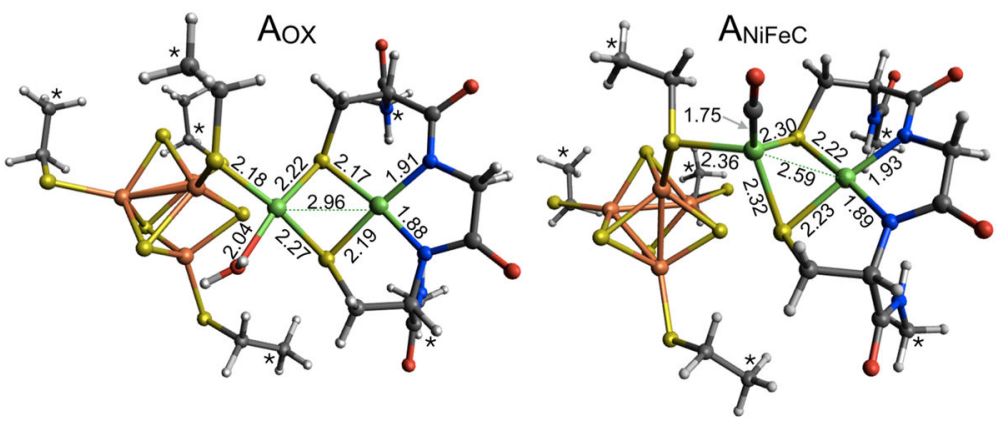

Figure 6.

DFT-calculated structures of oxidized and CO-bound forms of ACS. DFT geometryoptimized structures of $\mathrm{A}_{\mathrm{OX}}$ (left) and $\mathrm{A}_{\mathrm{NiFeC}}$ (right). The $\mathrm{Ca}$ atoms marked with an asterisk have been fixed to the crystal structure positions. The $\mathrm{Ni}_{\mathrm{p}}$ site is square-planar in $\mathrm{A}_{\mathrm{OX}}\left(\mathrm{Ni}-\mathrm{S}-\mathrm{S}-\mathrm{S}\right.$ dihedral angle of $\left.5^{\circ}\right)$ and tetrahedral in $\mathrm{A}_{\mathrm{NiFeC}}(\mathrm{Ni}-\mathrm{S}-\mathrm{S}-\mathrm{S}$ dihedral angle of $\left.55^{\circ}\right)$. Ni-Fe: $2.87 \AA\left(\mathrm{A}_{\mathrm{OX}}\right)$ and $3.93 \AA\left(\mathrm{A}_{\mathrm{NiFeC}}\right)$. 


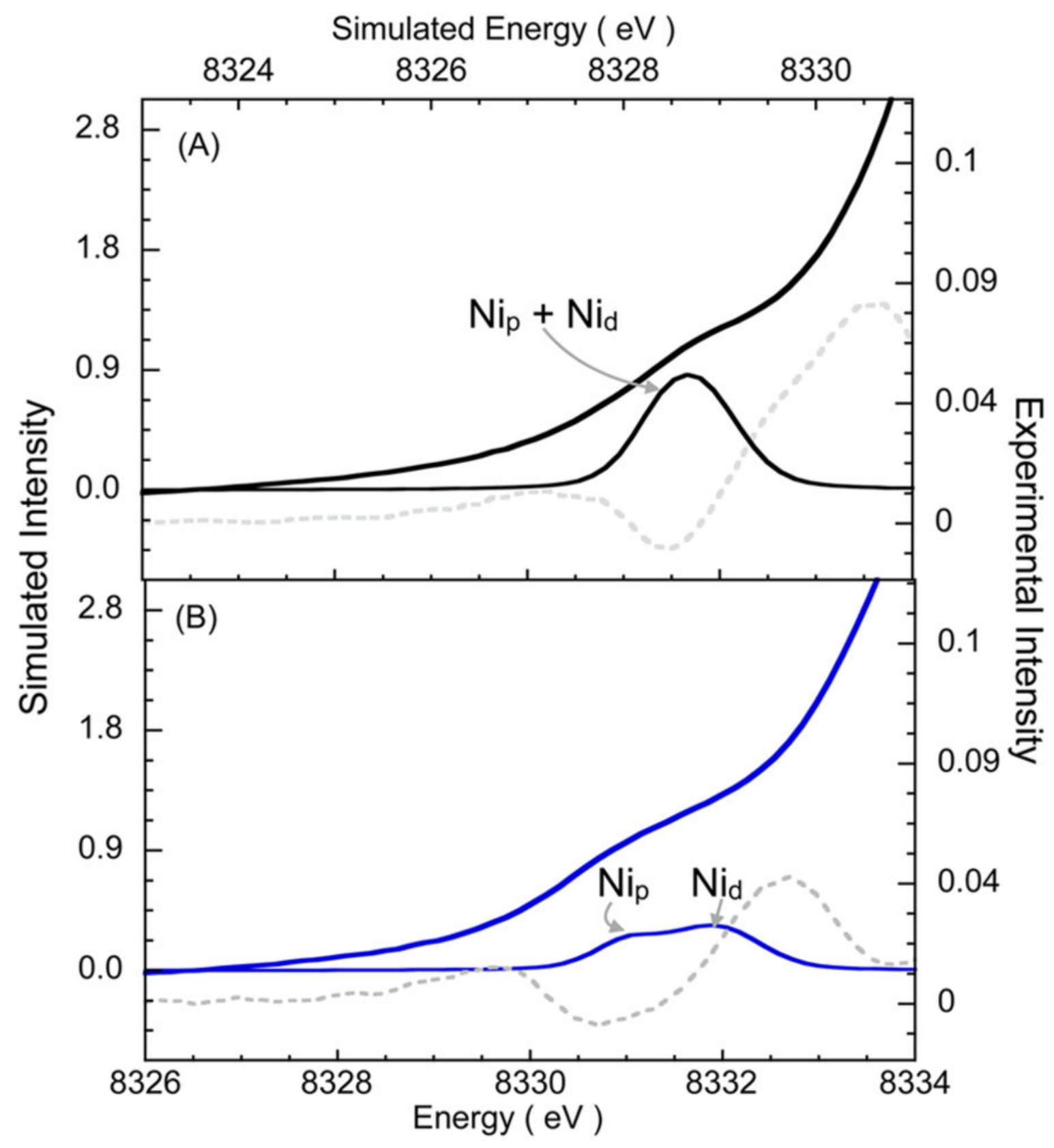

Figure 7.

TD-DFT-calculated XAS spectra. TD-DFT-calculated $1 \mathrm{~s} \rightarrow 3 \mathrm{~d}$ data compared to the Ni Kpre-edge data (-) and their second derivatives (---) for (A) $\mathrm{A}_{\mathrm{OX}}$ and (B) $\mathrm{A}_{\mathrm{NiFeC}}$ using the structures depicted in Figure 6. The arrows indicate the dominant contribution of $\mathrm{Ni}_{\mathrm{p}}$ and $\mathrm{Ni}_{\mathrm{d}}$ sites to individual pre-edge features. 

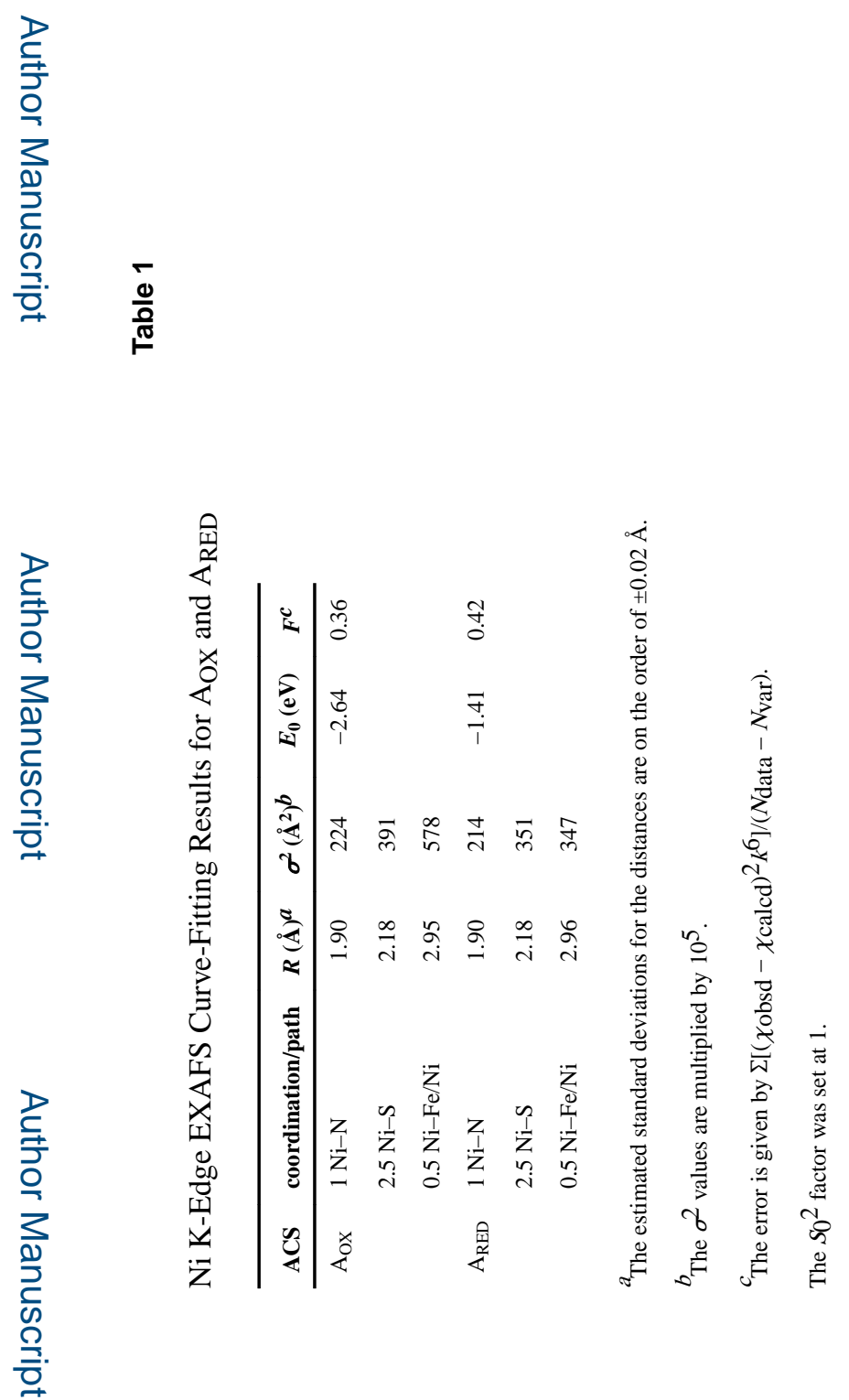

Biochemistry. Author manuscript; available in PMC 2017 December 01. 

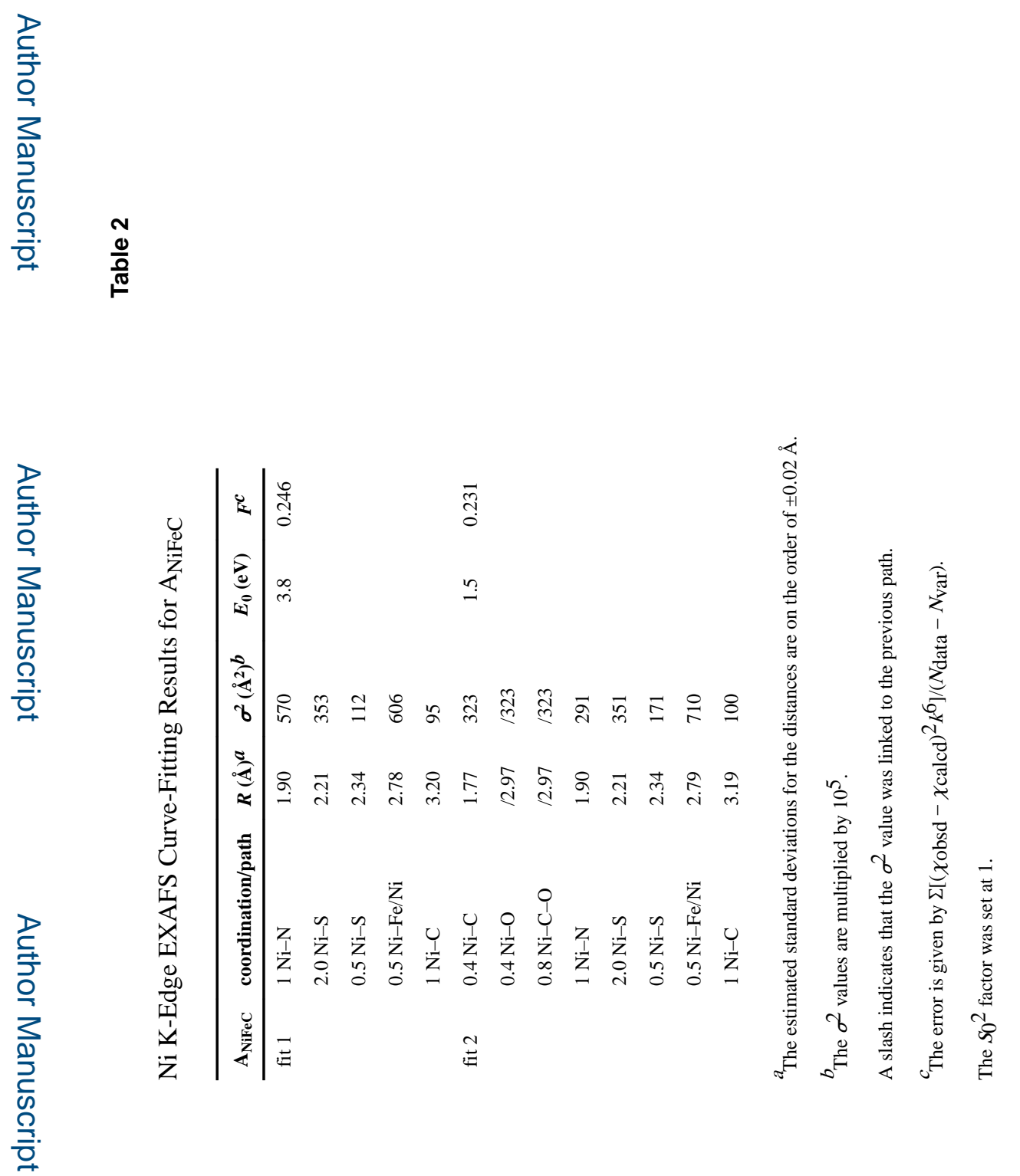

Biochemistry. Author manuscript; available in PMC 2017 December 01. 